\title{
PREFERENCIA Y RANGOS DE TOLERANCIA A LA TEMPERATURA Y SALINIDAD DE LOS PTERÓPODOS Y HETERÓPODOS FRENTE A LA COSTA ECUATORIANA*
}

Manuel Cruz ${ }^{(1)}$

\section{RESUMEN}

Del análisis de 216 muestras de zooplancton, obtenidas mensualmente desde 1990 hasta el 2007, en la estación fija a 10 millas de la costa ecuatoriana, frente a Salinas, Ecuador, se identificaron 14 especies de gasterópodos planctónicos (Pterópodos y heterópodos) a los que se le analizaron la preferencias de las masas de aguas y sus rangos de tolerancia a la temperatura y salinidad en el mar.

Los registros mensuales de la temperatura y salinidad superficial del agua, fueron relacionados con la abundancia de cada especie en un diagrama T-S (Temperatura y Salinidad) donde se observa la distribución y preferencia de la especie, mientras que en una tabla con las temperaturas y salinidades mínimas y máximas registradas mensualmente en la estación fija, se seleccionó los rangos de la temperatura y salinidad en que se presentó cada especie y se escogieron las 3 mejores abundancias, para definir la preferencia del tipo de masas de agua, esta información se ubicó en una figura con los diferentes tipos de aguas identificadas por (Enfield, 1976) en la que se graficaron las mínimas y máximas abundancias donde se aprecia el tipo de agua donde se presentaron, de lo cual se clasificaron las especies de la siguiente manera:

Euritermos: Creseis vírgula, Creseis acicula, Cavolinia uncinata, Limacina trochiformis y Atlanta gaudichaudi, Atlanta lesueuri y Firoloida desmarestia. Estenotermos: Hyalocylis striata, Atlanta peroni, Atlanta turriculata, Desmopterus papilio, Cavolinia longirostris, Diacria quadridentata, y Limacina bulimoides. Eurihalinos: Creseis vírgula, Hyalocylis striata, Atlanta lesueuri, Atlanta peroni, Diacria quadridentata, Atlanta gaudichaudi. Estenohalinos: Creseis acicula, Atlanta turriculata, Firoloida desmarestia, Desmopterus papilio, Cavolinia longirostris, Limacina bulimoides, Cavolinia uncinata, y Limacina trochiformis

Palabras claves: Tolerancia, temperatura, salinidad, Pterópodos, heterópodos, Ecuador

(1)

Tesis de Magister (Parte). Fac. Ciencias Naturales, Universidad. de Guayaquil

Instituto Oceanográfico de la Armada. Base Naval Sur-Vía a Pto. Marítimo-Av. 25 de Julio. Guayaquil-Ecuador

E-mail: mcruz@inocar.mil.ec; mcruzp47@yahoo.com 


\begin{abstract}
Of the analysis of 216 zooplankton samples, obtained monthly from 1990 to 2007, in the station to 10 miles of the Ecuadorian coast, in front of Salinas, Ecuador, 14 species of planktonics gastropods were identified (Pteropods and heteropods) to which analyzed the preferences of the waters masses and their ranks of tolerance to the temperature and salinity in the sea.

The monthly registries of the surface temperature and salinity of the water, were related with the abundance of each species in a diagram T-S (Temperature and Salinity) where is observed the distribution and preference of the species, whereas in a table with the minimum and maximum temperatures and salinities registered monthly in the fixed station, it selected the ranks of the temperature and salinity in which each species appeared and chose the 3 higher abundances, to define the preference of the type of water masses, this information was located in a figure with the different types from waters identified by (Enfield, 1976) in which were registered the minims and principles abundances where the type of water is appraised where presented/displayed, of which the species of the following way were classified:

Euritermos: Creseis vírgula, Creseis acicula, Cavolinia uncinata, Limacina trochiformis Atlanta gaudichaudi, Atlanta lesueuri and Firoloida desmarestia. Estenotermos: Hyalocylis striata, Atlanta peroni, Atlanta turriculata, Desmopterus papilio, Cavolinia longirostris, Diacria quadridentata, and Limacina bulimoides. Eurihalinos: Creseis vírgula, Hyalocylis striata, Atlanta lesueuri, Atlanta peroni, Diacria quadridentata, Atlanta gaudichaudi. Estenohalinos: Creseis acicula, Atlanta turriculata, Firoloida desmarestia, Desmopterus papilio, Cavolinia longirostris, Limacina bulimoides, Cavolinia uncinata, and Limacina trochiformis.
\end{abstract}

Key words: Tolerance, temperature, salinity, pteropods, heteropods, Ecuador 


\section{INTRODUCCIÓN}

El estudio sobre la tolerancia a la temperatura y salinidad se aplica mucho a las especies de importancia comercial, para conocer el medio mas apropiado para su cultivo, como en el camarón Penaeus vannamei que tolera un amplio rango de salinidad, desde 0,5-45 ppt, se siente cómodo entre 7-34 ppt pero crece particularmente bien en bajas salinidades entre 10-15 ppt (1)

Una realidad actual es el cambio climático y la contaminación, hacen que los ecosistemas acuáticos estén constantemente modificándose $\mathrm{y}$ es necesario conocer sus rangos de tolerancia para conocer la capacidad que tendrían las especies de adaptarse o desaparecer (2), pero en las especies marinas con importancia ecológica para interpretar ecosistemas y masas de aguas, hay poca información.

Desde el año 1990 hasta la actualidad han ocurrido siete eventos cálidos de El Niño y seis eventos fríos de La Niña en el Pacífico central, que tienen efectos principalmente frente a la costa ecuatoriana, donde generalmente se presentan situaciones climáticas extremas como las inundaciones, deslaves, es afectado el transporte y las comunicaciones, la agricultura, pesca, afectando el sector social y la economía del país por esa razón es necesario buscar nuevas alternativas como conocer mejor el comportamiento de las especies bioindicadores de masas de aguas y su tolerancia a la temperatura y salinidad, que ayuden a interpretar con más eficiencia qué tipo de masas de aguas se encuentran frente a la costa Ecuatoriana, para enfrentar con anticipación estos eventos naturales, informar a la comunidad para así disminuir los riesgos e impactos socio-económicos, que le cuesta cientos de millones de dólares al gobierno ecuatoriano.
Sobre las especies marinas se han publicado sobre indicadoras de El Niño como el de Miró y Luzuriaga (1974), quienes dan a conocer que los foraminíferos planctónicos son especies que pueden ser utilizados para identificar los diferentes tipos de masas de agua en el mar ecuatoriano. Luzuriaga, (1980), determina como especie de aguas cálidas a Globigerinoides ruber, de aguas frías a Globigerina bulloides y de aguas de mezcla a Globoquadrina dutertrei.

Las investigaciones sobre bioindicadores de masas de agua, se incrementaron con la creación de las estaciones fijas de La Libertad y Manta en 1990, donde se iniciaron las investigaciones de los pterópodos y heterópodos como indicadores de masas de agua, y desde 1997 se incorporaron las especies de diatomeas, dinoflagelados y quetognatos. Considerando, que es prioritario para el investigador biólogo identificar el hábitat que prefiere cada especie, en este trabajo se da a conocer la preferencia y la tolerancia a la temperatura y salinidad que tiene cada especie de Pterópodo y Heterópodo obtenidos a 10 millas de la costa ecuatoriana, para lo cual se ha considerado la información mensual de 17 años de investigación, desde 1990 al 2007.

Es importante agregar que para la interpretación las masas de aguas e interpretar el verdadero hábitat de la especie, hay que considerar su abundancia, el desarrollo morfológico, si son adultos o juveniles y la calcificación de sus conchas entre otras características.

\section{ANTECEDENTES}

Los estudios más antiguos sobre los pterópodos y heterópodos, se encuentran en los reportes de las expediciones científicas extranjeras del "Voyage of H.M.S. Challenger" realizado en los años $1873-1876$, reportado hace más de 
ciento veinte años por Pelsener en 1888 (Tesch, 1946), quien da a conocer las características taxonómicas de los gasterópodos planctónicos del océano Atlántico, que tienen concha calcárea, y son denominados pterópodos tecosomados.

Otros reportes que han contribuido al mejor conocimiento de la taxonomía de los pterópodos tecosomados, es el "Siboga Expedition", realizado en 1899-1900 y reportado por Tesch, 1904 (en Matsubara, 1975), y el "Dana Expedition", realizado en 1921-1922 en el Atlántico norte (en Matsubara, op cit.).

Después de los trabajos taxonómicos, aparecen las publicaciones de Souleyet, Boas, Pelsener y Meisenhelmer que contribuyeron mucho en la descripción morfológica y fisiología de los pterópodos tecosomados (Tesch, 1946).

Posteriormente, las especies de pterópodos se relacionan con el medio ambiente y es Tokioka, (1951) quien menciona que hay especies que son típicas de aguas costeras en el Pacífico y en el Atlántico Tropical como Creseis chierchiae, esto ha sido comprobado por Cruz, (1983) al haber reportado esta especie en el Golfo de Guayaquil, pero solo en la plataforma continental donde se presenta influencia de aguas del Río Guayas, en un ambiente estuarino, encontrándose ausente en las estaciones más alejadas, que se localizaban fuera de la plataforma continental, donde había una influencia de aguas oceánicas. Esta especie no ha sido reportada para las estaciones fijas de La Libertad y de Manta que se localiza en: $0^{\circ}$ $52^{\prime} 60^{\prime \prime}$ lat. S y $80^{\circ} 49^{\prime} 60^{\prime \prime}$ Long. W.

Otra especie que ha sido considerada como indicadora de aguas neríticas y regiones someras es Creseis acicula (Matsubara, 1975), que también ha sido denominada como una especie seminerítica para el Atlántico sur (Boltovskoy, 1981).

Magaldi, (1974), considera que las menores temperaturas pueden ser un limitante afectando negativamente a ciertas especies como a Limacina inflata, considerando a esta especie como típica de aguas cálidas. Otras especies, que solo habitan en las profundidades como Limacina helicoides, es considerada como batipelágica (Matsubara, 1975)

Existen otras especies de pterópodos como Creseis virgula que en el Atlántico es considerada como eurihalina, la que no presenta ciclo nictimeral (Frontier, 1965) y en el mar de China tiene una abundancia bianual y está relacionada con los vientos monzones (Matsubara, op cit).

En el océano Pacífico, uno de los trabajos que compila muchas publicaciones sobre los moluscos planctónicos, como los pterópodos y heterópodos que existen en la provincia Biogeográfica Panameña o Panámica, que comprende desde Baja California hasta el norte del Perú es el de Keen, (1971), quien menciona que tienen concha calcárea, pie reducido, con rádula y que algunos tienen ctenidios. Esta autora solo publica los nombres a nivel de especie y en algunas de ellas da a conocer su localidad, sin mencionar las características taxonómicas de estos moluscos pelágicos. En su trabajo, no menciona que son bioindicadores de masas de agua, o de ecosistemas marinos.

Esta autora reporta para la provincia Panámica EN el océano Pacífico 21 especies de heterópodos de las cuales, 5 (cinco) especies se han observado 10 millas de la costa ecuatoriana: Atlanta gaudichaudi, A. lesueuri, A. peroni, A. turriculata y Firoloida desmarestia (Cruz, 1998). 
Keen, (1971), también reporta 20 especies de pterópodos tecosomados para la Provincia Panámica, de las cuales 9 (nueve) especies se han encontradas a 10 millas de la costa ecuatoriana: C. longirostris, $C$. uncinata, $C$. pyramidata, Creseis acicula, C. virgula, Diacria quadridentata, Hyalocylis striata, Limacina bulimoides, L. trochiformis.

Hay una especie que no ha sido reportada por Keen, (1971), es el Pseudotecosomado Desmopterus papilio, especie que fue encontrada por primera vez a 10 millas de la costa ecuatoriana el 15 de julio de 1991 en aguas con temperatura de $24,5^{\circ} \mathrm{C}$, salinidad 34,3 ups, Nitrato 4,2 umol/L y Silicato 2,7 umol/L. lo que indicaría una preferencia por aguas de mezcla entre Aguas Tropicales Superficiales (ATS) y Aguas Subtropicales Superficiales (ASS).

Uno de los primeros trabajos publicados en el Ecuador utilizando las especies zooplanctónicas marinas como indicadores de masas de aguas es el de Miró y Luzuriaga (1974) quienes dan a conocer los resultados del crucero ORIÓN realizado en 1971, mencionando que las especies de foraminíferos planctónicos son organismos bioindicadores de masas de aguas.

Jiménez (1975) encontró en el Golfo de Guayaquil que cuando los dinoflagelados son muy abundantes, la productividad del mar era pobre y las diatomeas presentaron una baja diversidad específica en diciembre de 1972.

Posteriormente, Luzuriaga de Cruz, (1976), estableció que en el mar ecuatoriano se observó el predominio de los foraminíferos planctónicos de aguas cálidas procedentes del norte como Globoquadrina dutertrei y Globorotalia menardii.

En el Instituto Oceanográfico de la Armada (INOCAR), con la asesoría del Dr. Serge
Frontier, especialista en pterópodos y heterópodos, se iniciaron las investigaciones sobre estos grupos de gasterópodos planctónicos en el Ecuador, desde julio de 1977 a septiembre de 1978.

En la década de 1980 a 1990, se intensificaron las investigaciones que relacionan las especies marinas con los diferentes ambientes incluyendo el frente ecuatorial, así tenemos que Jiménez y Bonilla (1980), reportan que en septiembre de 1974 el frente ecuatorial estuvo bien desarrollado mostrando un gradiente de temperatura entre $18^{\circ} \mathrm{C}$ y $24^{\circ} \mathrm{C}$, y salinidades entre 33,0 ups y 35 ups y que las altas biomasas de macro-zooplancton se ubicaron en la parte sur del frente, así como en las aguas intermedias o de transición.

Durante el evento El Niño de diciembre de 1972, se encontró que cuando predominan los dinoflagelados sobre las diatomeas, el género más abundante es Ceratium sp., las aguas son relativamente pobres y están relacionadas con temperaturas altas de $25,5^{\circ} \mathrm{C}$ y $27,5^{\circ} \mathrm{C}$ con salinidades de 32 ups y 33,8 ups. (Pesantes, 1980),

Mientras en Ecuador, se estaban iniciando las investigaciones sobre pterópodos y heterópodos, Van der Spoel y Boltovskoy (1981), utilizaron a los pterópodos tecosomados como organismos bioindicadores para definir y determinar las diferentes provincias biogeográficas en el Atlántico Sudoccidental, demostrando su importancia para caracterizar las masas de agua en base a la asociación faunística que forman estos gasterópodos planctónicos, reconociendo que en la Corriente de Brasil predomina Stiliola subula, y en los trópicos Creseis virgula $f$. conica. En cambio Creseis acicula está asociada a las aguas neríticas y costeras. De igual forma las especies Antárticas están representadas por Clio pyramidata f. sulcata $y$ 
Limacina helicina f. antartica, mientras que las especies subantárticas, por Clio pyramidata $f$. antartica y Spongiobranchea australis. Además, el pterópodo pseudotecosomado Desmopterus papillo es común en el océano Indico.

Con la referencia de que los pterópodos tecosomados son considerados como bioindicadores de masas de agua y ecosistemas marinos, en el Ecuador, Cruz (1983), en el primer trabajo sobre este grupo de gasterópodos planctónicos, reporta tres especies de pterópodos tecosomados para el Golfo de Guayaquil, en los alrededores de la isla Puná, que incluye parte del Canal de Cascajal, Canal de Jambelí y el sur-oeste de la isla Puná.

En el mismo año, Cruz, (1983), reporta siete (7) especies de gasterópodos planctónicos: 5 pterópodos tecosomados: Creseis chierchiae, Creseis virgula, Creseis acicula, Limacina trochiformis, Limacina inflata y dos heterópodos: Atlanta gaudichaudi y Atlanta lesueuri, mencionando sus características taxonómicas y sus ambientes como resultado del análisis de 4 cruceros en el Golfo de Guayaquil, en mayo 1973, febrero 1978, marzo 1982 y noviembre 1983.

Bonilla, (1983) en su trabajo sobre El zooplancton de las Islas Galápagos durante 1995 y 1996, reporta a nivel de grupo, que los pterópodos ocupan el segundo lugar en abundancia con el $11 \%$.

En el país, se continúa aportando con publicaciones sobre las especies planctónicas marinas y es Jiménez, (1983), que en su publicación del catálogo Diatomeas y silicoflagelados del Golfo de Guayaquil (II edición), reporta 189 especies y variedades de diatomeas y silicoflagelados, siendo la mayoría los primeros registros para el Ecuador, agregando datos de su ambiente y el ecosistema donde fueron encontradas cada una de las especies.

Pesantes, (1983) considera a las especies de dinoflagelados, como indicadores de los avances del agua cálida y de baja salinidad, hacia el sur, que se presentaron en diciembre durante El Niño 1972

Existen evidencias que hay especies marinas que caracterizan las masas de agua en los océanos del mundo, pero es necesario comprender mejor el desplazamiento de las masas de agua utilizando a los organismos marinos como bioindicadores. Cruz, (1996), en su trabajo de "Pterópodos tecosomados y Heterópodos (Gasterópodos) como bioindicadores del Evento "El Niño" 1992, en la estación fija "La Libertad", Ecuador, relacionó a estas especies con el Evento cálido "El Niño" y reportó 14 especies, nueve (9) especies de pterópodos tecosomados y 5 heterópodos, enfatizando que la interpretación de los ecosistemas marinos se realizó considerando las diferentes asociaciones de las especies, además reconoció que Hyalocylis striata es una especie que siempre está asociada a masas de aguas cálidas, incluyendo claves taxonómicas, pero no relacionó a estas especies con los parámetros físicos- químicos.

Dos años después, luego de haberse presentado en el océano Pacífico el Evento cálido El Niño 1997-1998, Cruz, (1998), publicó “Gasterópodos planctónicos (Pterópodos y Heterópodos) como bioindicadores de los eventos "El Niño" 1992 y 1997-1998 en la estación fija "La Libertad", Ecuador. Este autor reportó 15 especies de pterópodos y heterópodos que se registraron frente a la costa ecuatoriana desde 1990 hasta 1998, y de las cuales 9 especies respondieron mejor a los cambios que ocurren en el mar ecuatoriano, y 6 no correspondieron a estas condiciones y fueron poco abundantes. 
El último trabajo publicado sobre los pterópodos y heterópodos en el Océano Pacífico es el de Cruz, (2005-2006), denominado "Determinación de los períodos cálidos (El Niño) y fríos (La Niña), en base al comportamiento mensual de los pterópodos $\mathrm{y}$ heterópodos, como Bioindicadores del ecosistema marino Ecuatoriano", menciona que de las 15 especies de pterópodos y heterópodos, solo nueve especies responden a los cambios en el ecosistema marino frente al Ecuador. De las nueve especies seleccionadas, hay cuatro: Hyalocylis striata, Creseis acicula, Atlanta peroni y Atlanta lesueuri que tienen una respuesta positiva aumentando su abundancia frente al Ecuador cuando se presentan aguas cálidas y coinciden con las anomalías positivas de la temperatura superficial que se presentan en el Pacífico central, publicado por la NOAA. Es importante mencionar, que ninguna de las especies es relacionada con la temperatura, salinidad ni parámetros químicos de la estación fija de "La Libertad".

De la bibliografía consultada se menciona la temperatura y salinidad donde se han encontrado las especies, pero no sus rangos de tolerancia, por lo que se puede manifestar que no se han encontrado trabajos o investigaciones publicadas sobre los rangos de tolerancia a la temperatura y salinidad de las especies marinas ecuatorrianas, por lo que este aporte será una contribución para incentivar este tipo de investigación.

\section{ÁREA DE STUDIO}

Para el estudio de la tolerancia a la temperatura y salinidad de quince (15) especies de gasterópodos planctónicos (Pterópodos y Heterópodos), se seleccionó la estación fija localizada a 10 millas de la costa ecuatoriana, frente a Salinas, donde hay más de 100 metros de profundidad y existe una influencia de masas de aguas oceánicas (Fig. 1).

El área de estudio está influenciada por dos épocas en el año: La época húmeda o lluviosa entre enero a abril y la época seca o no lluviosa entre mayo a diciembre.

En la época lluviosa, la posición del sol se localiza en el Hemisferio sur, por lo que los días son más largos que las noches, el hemisferio sur está más caliente que el Hemisferio norte, por lo que los vientos alisios del norte soplan con más fuerza que los vientos alisios del sur. Esta condición permite que la Zona de Convergencia Intertropical (ZCIT) se desplace hacia el sur y se localice sobre el territorio ecuatoriano, mientras que el ecosistema de la corriente de Humboldt denominada Aguas Costeras Peruanas (ACP), o Aguas Costeras de Humboldt (ACH), se debilita y se caracteriza por tener una temperatura menor a $21^{\circ}$ Centígrados y una salinidad mayor a 34,9 por mil (Enfield, 1976). Las aguas tropicales del norte, caracterizadas por tener una temperatura mayor a $25^{\circ}$ Centígrados y una baja salinidad, menor a 33 ups (Enfield, 1976), proveniente de la Bahía de Panamá, se desplazan hacia el sur, llegando hasta los límites sur del Ecuador y en consecuencia el mar ecuatoriano tiene Aguas Ecuatoriales Superficiales (AES) con temperatura de 21 a $25^{\circ} \mathrm{C}$ y salinidad de 33 a 34,5 ups (Enfield, 1976). (Tabla 1)

Tabla. 1.- Tipos de masas de aguas que pueden encontrarse frente a la costa Ecuatoriana (Enfield, 1976)

\begin{tabular}{|l|c|c|}
\hline \multicolumn{1}{|c|}{ Tipo de masa de agua } & Temperatura & $\underline{\text { Salinidad }}$ \\
\hline Aguas Subtropicales Superficiales (ASS) & $>25^{\circ} \mathrm{C}$ & $>35$ ups \\
\hline Aguas Tropicales Superficiales (ATS) & $>25^{\circ} \mathrm{C}$ & $<33.0$ ups \\
\hline Aguas Ecuatoriales Superficiales (AES) & $21^{\circ} \mathrm{C} \mathrm{a} 25^{\circ} \mathrm{C}$ & 33.0 a 34,5 ups \\
\hline Aguas Costeras de Humboldt (ACH) & $<21^{\circ}$ & $>34,9$ ups \\
\hline
\end{tabular}


Cuando ocurre un evento El Niño, esta condición meteorológica y oceanográfica, permite que aguas cálidas del Pacífico central con más de $28^{\circ} \mathrm{C}$, lleguen a la Bahía de Panamá, se desplacen hacia el sur y

permanezcan frente a Ecuador y Perú, favoreciendo la evaporación del agua, formando nubes convectivas y la correspondiente precipitación.

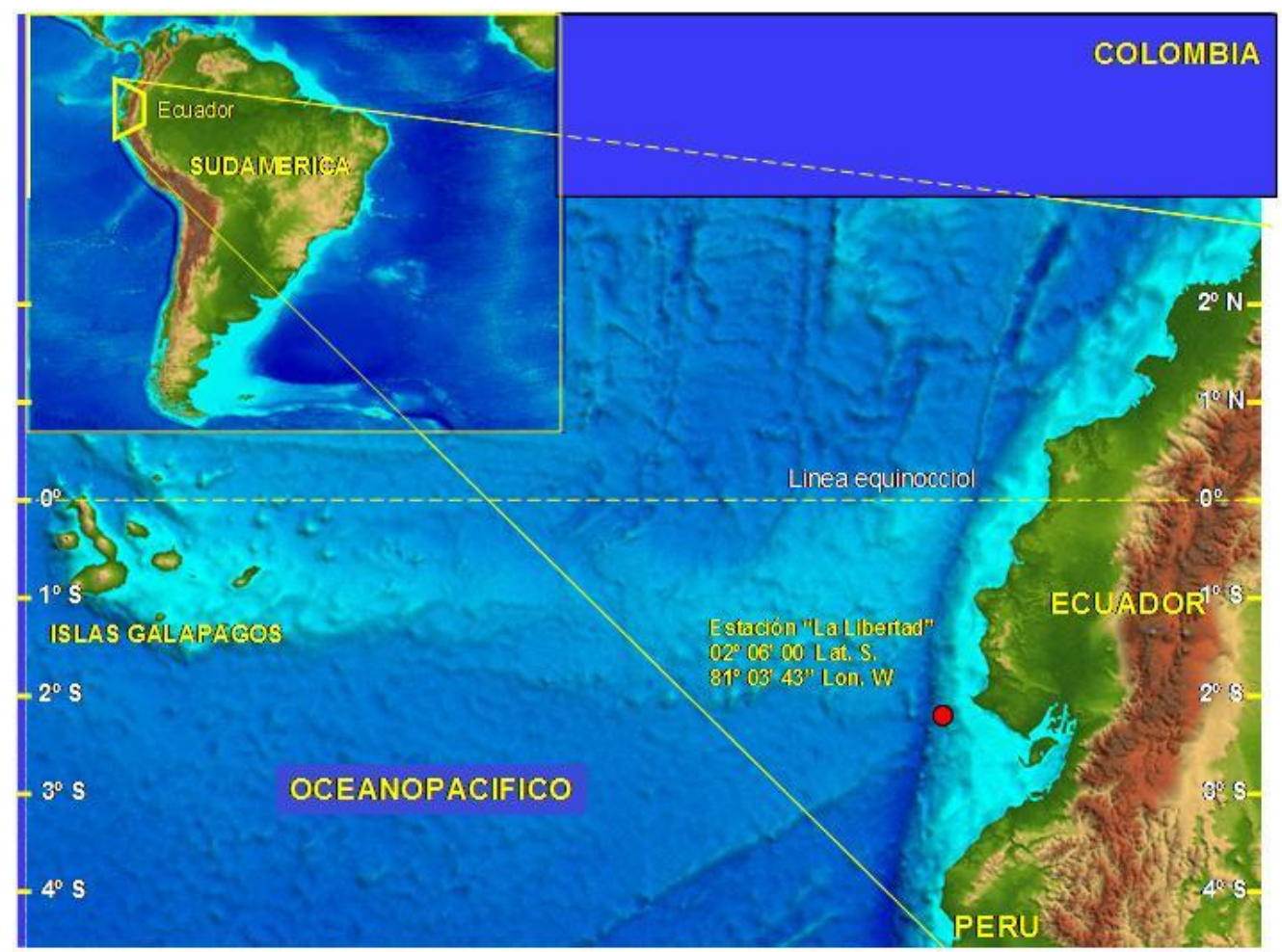

Fig. 1.- Posición de la estación fija de "La Libertad”

En la época seca entre Mayo a Diciembre, el sol se desplaza hacia el hemisferio norte, el cual se calienta más que el del sur, los vientos alisios del sur soplan con mayor fuerza, produciendo los afloramientos costeros de la corriente de Humboldt, estas aguas frías se desplazan hacia el norte y a la altura del Ecuador, giran hacia el oeste del Océano Pacífico debido a la fuerza de Coriolis. De igual forma, la Zona de Convergencia Intertropical (ZCIT), se desplaza hacia el norte localizándose entre los $5^{\circ}$ a $10^{\circ}$ de Latitud norte, terminándose las lluvias en el Ecuador.

Las aguas frías de la corriente de Humboldt, más el producto de los afloramientos costeros generados por los vientos alisios, desplazan aguas frías hacia el Ecuador, que en muchas ocasiones pueden llegan hasta el norte del país,
Provincia de Esmeraldas, formando un frente Ecuatorial al mezclarse las aguas frías y salinas del sur, con las aguas tropicales cálidas y poco salinas del norte.

Estas dos épocas existentes en el Ecuador, hacen que la estación Fija de "La Libertad", esté influenciada por aguas frías de Humboldt entre mayo a diciembre y disminuya su influencia entre enero a abril.

Todos estos cambios hacen interesante y más complejos las masas de aguas que existen frente al Ecuador, por eso es un requerimiento indispensable que se conozca los rangos de tolerancia a la temperatura y salinidad que tiene cada especie que sea utilizada como bioindicador de un ecosistema. 


\section{MATERIALES Y MÉTODOS}

La metodología utilizada es de campo y de laboratorio.

\section{De Campo}

Desde la selección de la Estación fija de "La Libertad", en junio de 1990, localizada a 10 millas de Salinas, la misma se encuentra a 100 $\mathrm{m}$ de profundidad, con influencia de aguas oceánicas. Se ha utilizado embarcaciones que están equipadas con GPS para su posicionamiento, y las comunicaciones necesarias propias de las embarcaciones navales, que brindan las seguridades para poder realizar la recolección de las muestras de zooplancton.

El equipo utilizado para la recolección de las muestras de zooplancton, consta de una red cónica tipo estándar, que tiene una boca de 32 $\mathrm{cm}$. de diámetro y un ojo de malla de nylon de 335 micras, considerada como la más adecuada para la recolección de los pterópodos y heterópodos (Comunicación personal con el Dr. Serge Frontier); el largo de la red es de un metro, más $20 \mathrm{~cm}$ del cubilete. El arrastre superficial fue realizado a una velocidad constante de dos nudos, durante diez minutos, dando aproximadamente un volumen de agua filtrada de $50 \mathrm{~m} 3$ (Fig. 2)

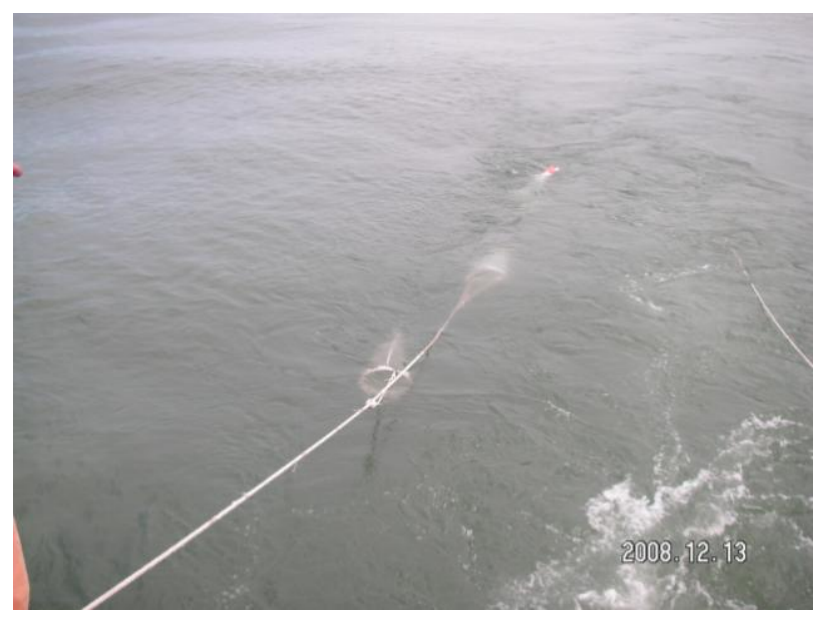

Fig. 2. Red de nylon recolectando el zooplancton
El plancton recolectado a bordo de la embarcación (Fig. 3), es fijado y preservado con formol al $5 \%$, neutralizado con tetra borato de sodio hasta un $\mathrm{pH}$ de 8 a 8,5 aproximadamente, que es el $\mathrm{pH}$ del agua de mar del sitio muestreado. La muestra es etiquetada para ser analizada en el laboratorio del INOCAR.

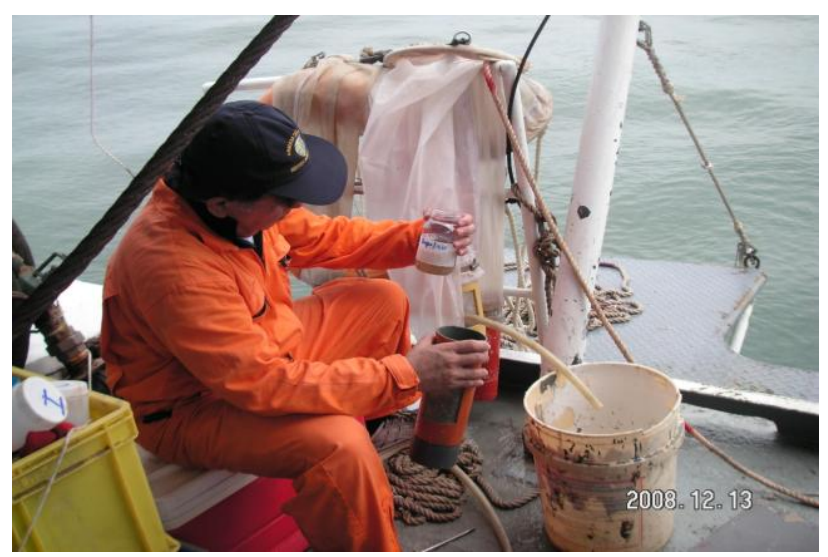

Fig. 3.- Obtención de la muestra de zooplancton

Para registrar la temperatura y salinidad desde la superficie hasta los $100 \mathrm{~m}$ de profundidad, se utilizó un CTD (Fig. 4), que es lanzado con un cabo de nylon a través de una polea. La información del CTD es procesada en el laboratorio con una computadora para extraer la información e ingresarla a la base de datos, para proceder a utilizarla y relacionarla con las especies de organismos Bioindicadores.

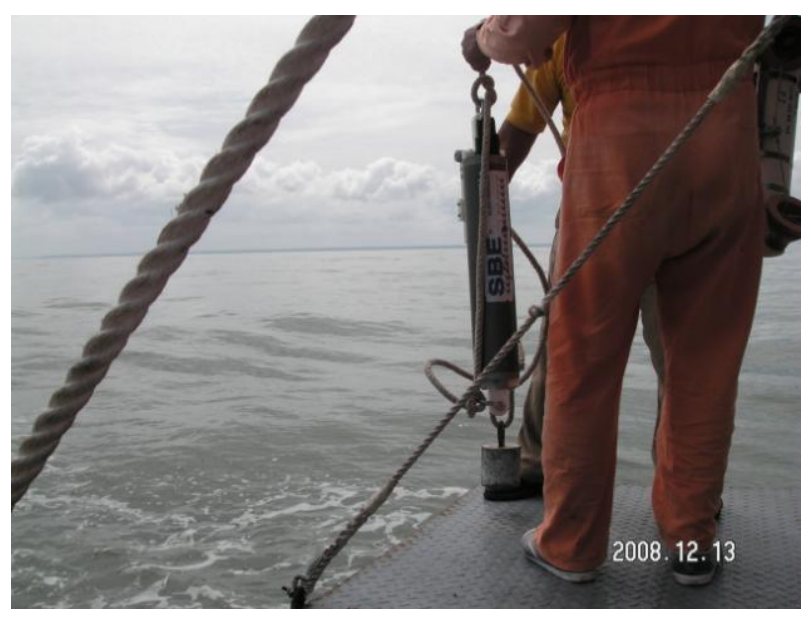

Fig. 4.-El equipo CTD, listo, antes de lanzarlo al mar. 


\section{De Laboratorio}

En el laboratorio de biología del INOCAR, se utiliza un estéreo-microscopio Zeiss de 80 aumentos y se analiza toda la muestra de zooplancton utilizando una cámara de Dolfus. Para su identificación se consultan textos especializados, que están mencionados en la bibliografía.

Las fotografías de los organismos fueron tomadas con una cámara fotográfica digital incorporada el estéreo-microscopio, y son utilizadas cuando las estructuras morfológicas son pequeñas y se desea observar características taxonómicas.

\section{ASPECTOS BIOLÓGICOS Y ECOLÓGICOS}

En cada tipo de agua hay especies marinas que toleran un amplio rango de temperatura (euritermos) y otras toleran un pequeño rango de temperatura (estenotermos), así como otras especies toleran también un amplio rango de salinidad (Eurihalinos) y otras soportan un pequeño rango de salinidad (Estenohalinos), conocer el tipo de agua o masa de agua en que prefieren vivir y sus rangos de tolerancia a la temperatura y salinidad, es básico para interpretar con la presencia de cada especie, el tipo de masa de agua que está presente y conocer mejor el ambiente marino en base a estas especies bioindicadoras como los pterópodos y heterópodos.

Para estos propósitos se ha relacionado cada especie con la temperatura y salinidad en un diagrama T-S, en la que se grafica cada especie encontrada con su menor y mayor temperatura y la menor y mayor salinidad, así como el tipo de masa de agua donde se presentó más abundante y está coloreada. Para graficar la abundancia se tomó el rango logarítmica según Frontier (1980). (Fig. 5)

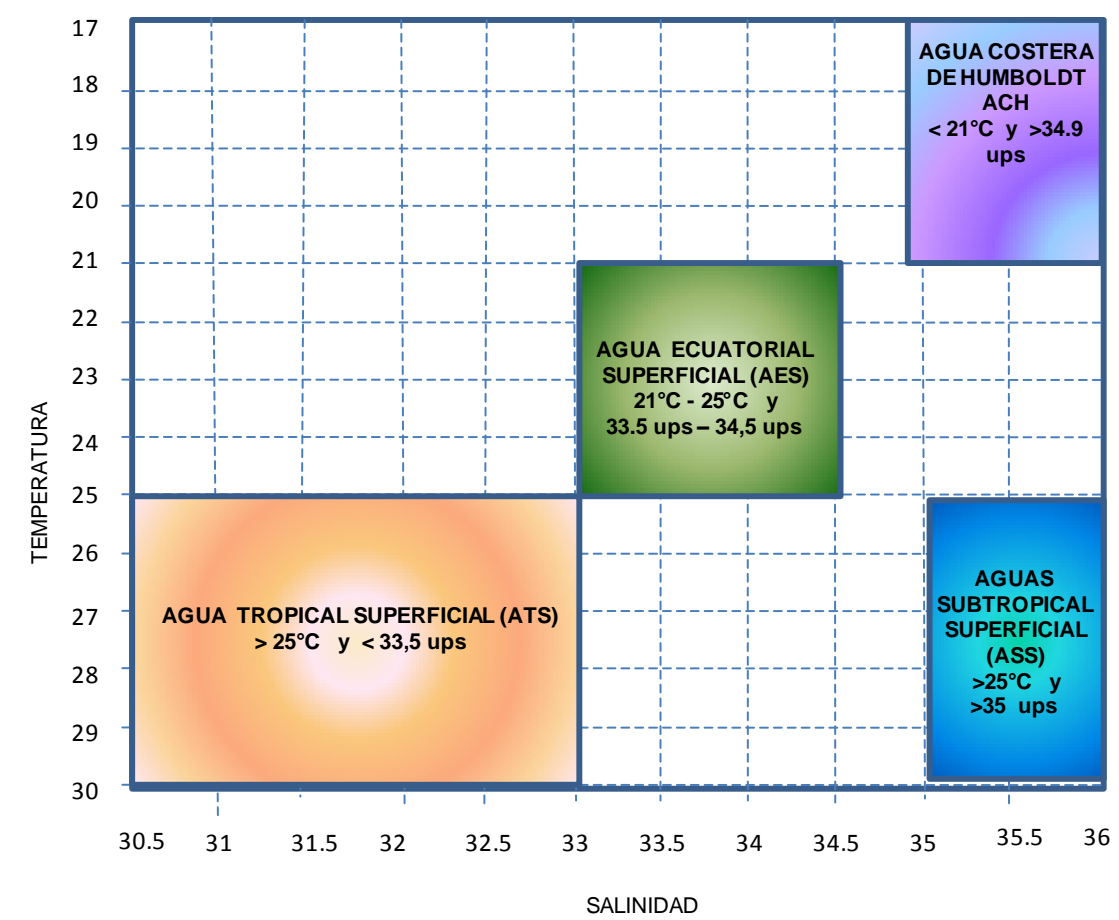

Rango de abundancia logarítmica Según Frontier (1980)

$\begin{array}{|lll|}\text { (C) } & \text { ESCASO } & 1-3 \\ \text { (O) } & \text { FRECUENTE } & 4-18 \\ (0 & \text { ABUNDANTE } & 19-80 \\ & \text { MUY ABUNDANTE } & 81-350\end{array}$

Fig. 5.- Diagrama de Temperatura y Salinidad (T-S), y las características de los tipos de masas de aguas en el océano Pacífico ecuatorial. (Según Enfield, 1976) 


\section{RESULTADOS}

Se han encontrado 14 especies de pterópodos y heterópodos en los estudios mensuales realizados en la estación fija de La Libertad, desde 1990 al 2007 y para poder utilizarlos como bioindicadores de masas de aguas, se da una breve descripción taxonómica de la especie.

A continuación se muestra el rango de la menor y mayor temperatura y salinidad en que se ha presentado la especie con la mínima abundancia (línea con dos flechas en las puntas) y en un cuadro resaltado o pintado, indica la temperatura y/o salinidad, preferida de la especie, producto de las tres mayores abundancias en que se ha presentado en 240 muestras mensuales, durante los 17 años de estudio desde 1990 hasta diciembre del 2007.

En la figura con los cuatro (4) tipos de aguas que se han encontrado frente al Ecuador, esta graficada la abundancia logarítmica según (Frontier, 1980) de la especie, indicando la preferencia de la masa de agua y la fecha en que se encontró la especie.

Se complementa la información con un diagrama T-S (temperatura y salinidad) en que observa en qué tipo de masa de agua fue encontrada la especie.

Phylum Mollusca:

Clase Gasterópoda

Familia CAVOLINIDAE

\section{Cavolinia longirostris (Blainville, 1821)}

Esta especie posee conchilla larvaria recta, truncada posteriormente, la abertura, no tiene opérculo y presenta labios finos, el superior se prolonga de forma curvado hacia la parte anterior que termina en punta ovalada en forma de rostro, lo que le da el nombre de la especie, el mayor diámetro de la concha está en la parte posterior a la altura de las espinas laterales (Spoel 1972), es epipelágica y de ambiente oceánico.

En este estudio se la considera estenoterma y estenohalina (Foto 1).

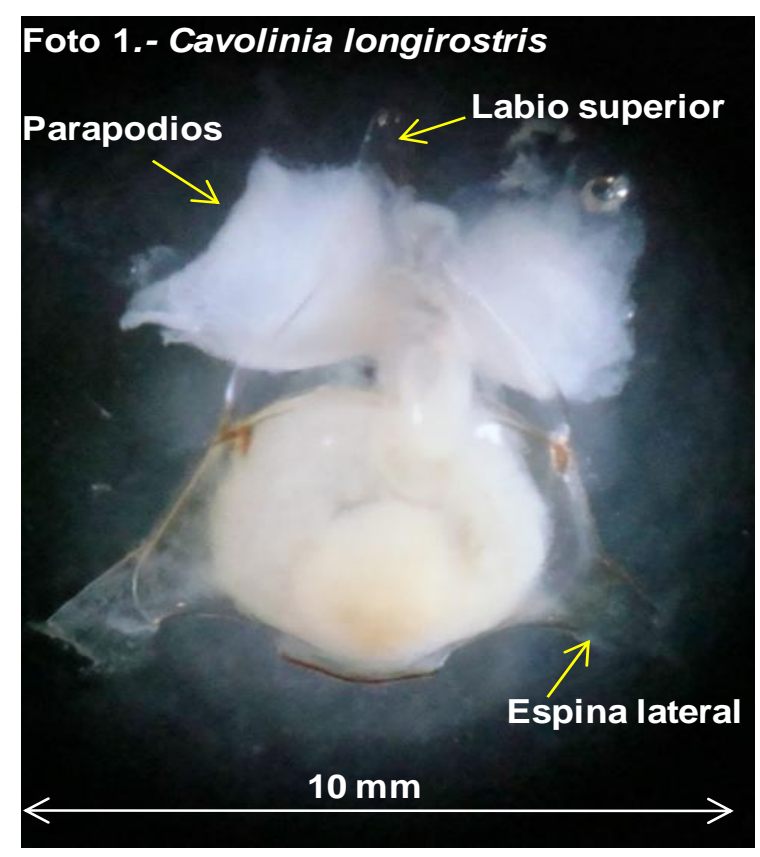

Cavolinia longirostris se ha presentado en temperaturas de $22^{\circ} \mathrm{C}$ a $27^{\circ} \mathrm{C}$ con preferencia entre $23.2^{\circ} \mathrm{C}$ a $24^{\circ} \mathrm{C}$ y en salinidades de 31.9 ups a 34.9 ups con preferencia 34 ups a 34.3 ups (Fig. 6).

\begin{tabular}{|c|c|c|c|c|c|c|c|c|c|c|c|c|c|c|c|c|c|c|c|c|c|c|c|c|}
\hline & & & & & & & T & E & M & P & E & $\mathrm{R}$ & A & $\begin{array}{r}\mathrm{T} \\
\mathrm{T}\end{array}$ & U & R & A & & & & & & & \\
\hline & $<T C$ & 18,9 & 19 & 19,5 & 20 & 20,5 & 21 & 21,5 & 22 & 22,5 & 23 & 23,5 & 24 & 24,5 & 25 & 25,5 & 26 & 26,5 & 27 & 27,5 & 28 & 28,5 & 29 & $29,5>T C$ \\
\hline & & & & & & & & & & & & & & & & & & & & & & & & \\
\hline \multirow[t]{6}{*}{ Cavolinia longirostris } & & & & & & & & & 22,5 & & & $23,2^{\circ}(2$ & $24^{\circ} \mathrm{C}$ & & & & & & & 27 & & & & \\
\hline & & & & & & & & & & & & & & & & & & & & & & & & \\
\hline & & & $s$ & A & L & 1 & N & 1 & D & A & D & & & & & & & & & & & & & \\
\hline & $<$ ups & 30 & 30,5 & 31 & 31,5 & 32 & 32,5 & 33 & 33,5 & 34 & 34,5 & & >ups & & & & & & & & & & & \\
\hline & & & & & & & & & & & & & & & & & & & & & & & & \\
\hline & & & & 31,9 & & & & & & 34 & 34,3 & & 34,9 & & & & & & & & & & & \\
\hline & & & & & & & & & & & & & & & & & & & & & & & & \\
\hline
\end{tabular}

Fig. 6.- Rangos de tolerancia y preferencia de la temperatura y salinidad de Cavolinia longirostris 
Se han encontrado 18 ejemplares en 6 observaciones realizadas con una abundancia máxima de 10 ejemplares, considerándose relativamente escasa y en una sola ocasión se presentó como frecuente.

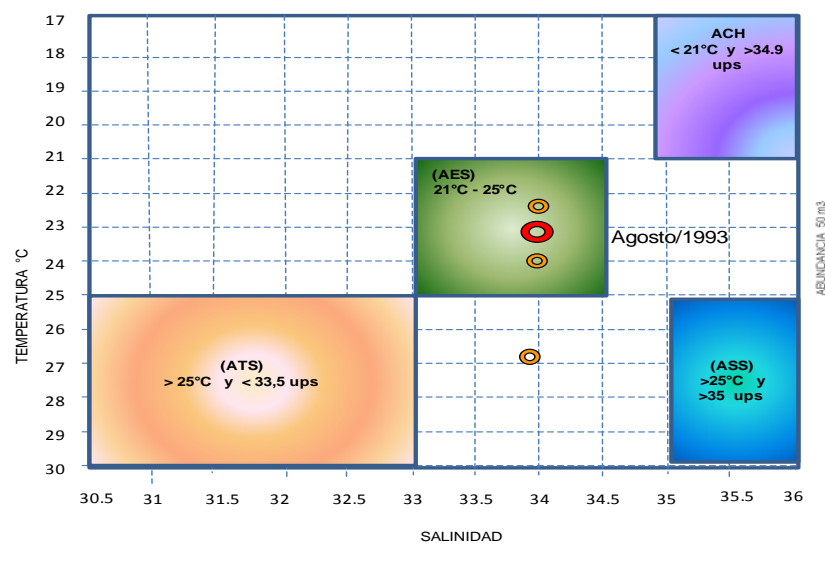

Fig. 7.- Cavolinia longirostris muestra preferencia por las Aguas Ecuatoriales Superficiales (AES) y una salinidad de 34 ups
En el diagrama T-S se observa que se la ha encontrado en Aguas Ecuatoriales Superficiales (AES), así como su mayor abundancia en agosto de 1993 (Fig. 7), cuando en la región 3.4 había un episodio neutral y en la región $1+2$ anomalías positivas de $0.27^{\circ} \mathrm{C}$ después de haberse presentado un evento El Niño.
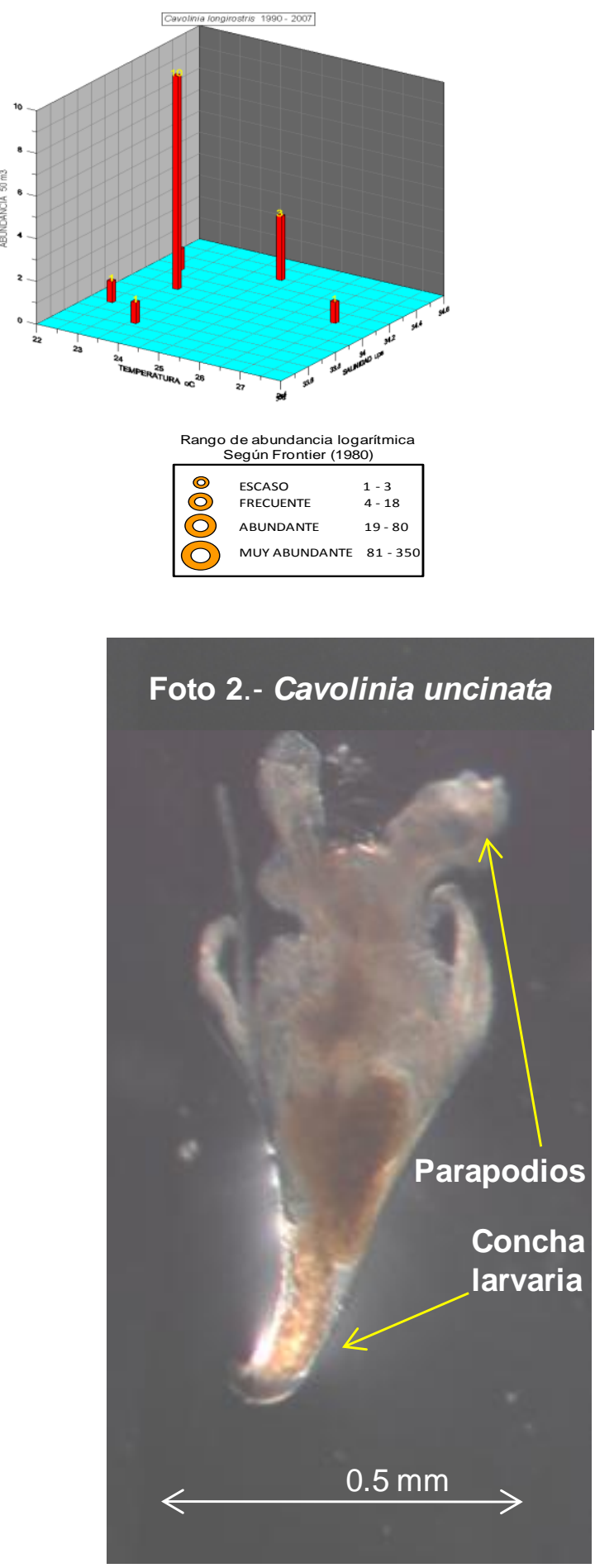

Cavolinia uncinata se ha presentado en temperaturas de $18.9^{\circ} \mathrm{C}$ a $26.5^{\circ} \mathrm{C}$ con preferencia entre $18.9^{\circ} \mathrm{C}$ a $24.5^{\circ} \mathrm{C}$ y en salinidades de

En este estudio se
estenohalina (foto 2) 
31.7 ups a 34.9 ups, con preferencia 33.3 ups a 34.3 ups (Fig. 8).

Se han encontrado 18 ejemplares en 6 observaciones realizadas con una abundancia máxima de 7 ejemplares, considerándose relativamente escasa y en una sola ocasión se presentó como frecuente muy similar a Cavolinia longirostris

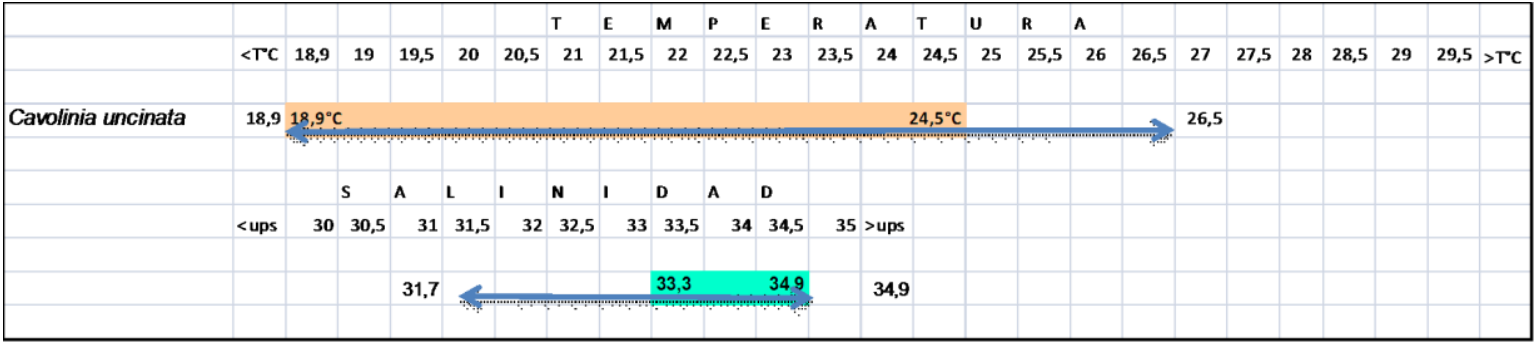

Fig. 8.- Rangos de tolerancia y preferencia de la temperatura y salinidad de Cavolinia uncinata
En el diagrama T-S se observa que Cavolinia uncinata con un amplio rango de temperatura y salinidad, sin preferencia por un tipo de agua. Su mayor abundancia se la encontró en Aguas Ecuatoriales Superficiales (AES) en octubre de
1993 (Fig. 9), cuando en la región 3.4 había un episodio neutral y en la región $1+2$ anomalías positivas de $0.11^{\circ} \mathrm{C}$ después de haberse presentado un evento El Niño.

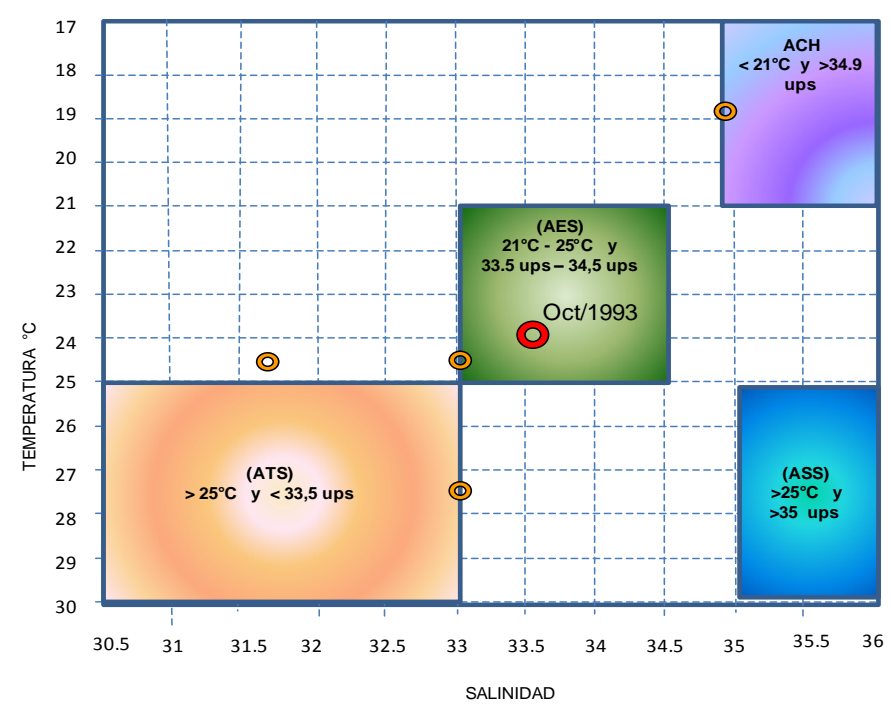

Fig. 9.- Cavolinia uncinata no muestra una preferencia por un tipo de agua, su Mayor abundancia se la encontró en Aguas Ecuatoriales Superficiales (AES)

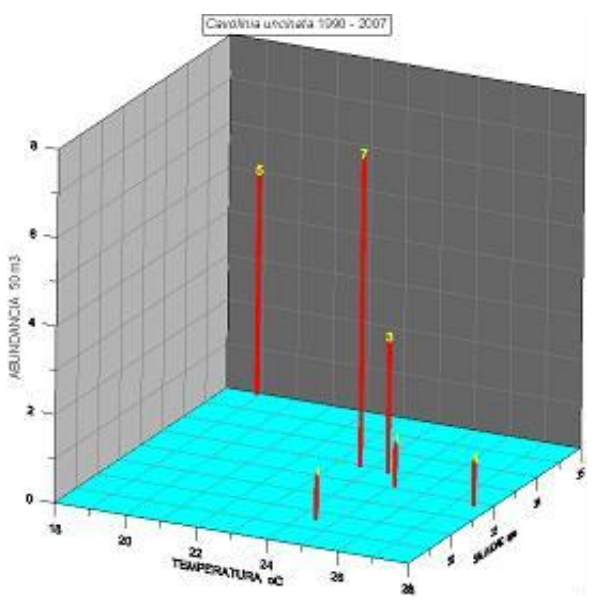

Rango de abundancia logarítmica Según Frontier (1980)

\begin{tabular}{|lll|}
\hline (2) & ESCASO & $1-3$ \\
()) & FRECUENTE & $4-18$ \\
(O) & ABUNDANTE & $19-80$ \\
() & MUY ABUNDANTE & $81-350$ \\
\hline
\end{tabular}

Observaciones: Cavolinia uncinata es una especie de ambiente oceánico, considerara rara, se la ha observado cuando hay anomalías positivas en la estación La Libertad con tendencia a preferir aguas de alta salinidad, cuando se ha presentado un evento El Niño, no se la ha observado. Por ser poco abundante no es considerada como un buen bioindicador de aguas cálidas. 


\section{Familia CAVOLINIIDAE} Creseis acicula (Rang, 1828)

Conchilla recta en forma de aguja, con una ligera constricción en la base que separa la concha larvaria del adulto (Frontier, 1963).
Las estrías de crecimiento no son visibles al microscopio óptico (Magaldi, 1974), se la reconoce porque el ángulo que forma es de $13.5^{\circ}$ a $14^{\circ}$ (Tokioka, 1955) (Foto 3). En este estudio ha tenido un comportamiento como una especie euriterma y estenohalina.

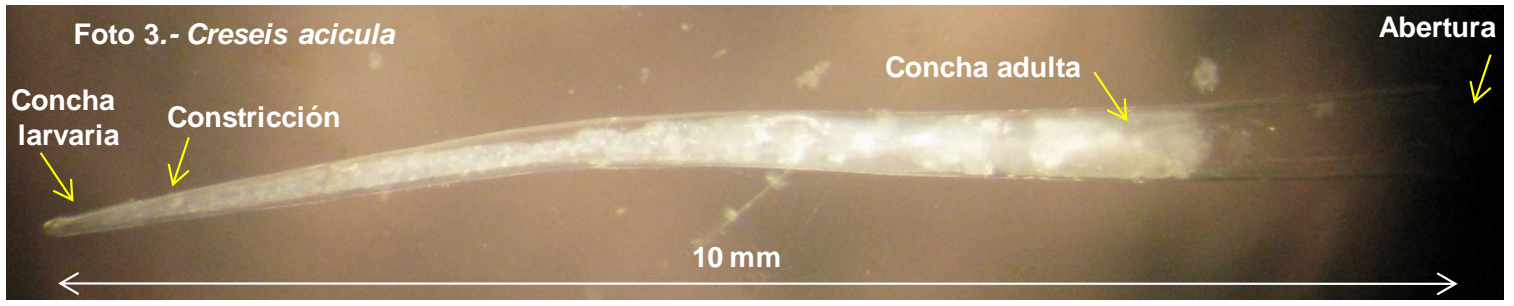

Creseis acicula se ha presentado en temperaturas de $18.9^{\circ} \mathrm{C}$ a $29.1^{\circ} \mathrm{C}$ con salinidades de 31.3 ups a 34.9 ups, con preferencia entre $23.2^{\circ} \mathrm{C}$ a $28.5^{\circ} \mathrm{C}$ y en preferencia de 33.4 ups a 34 ups (Fig. 10).

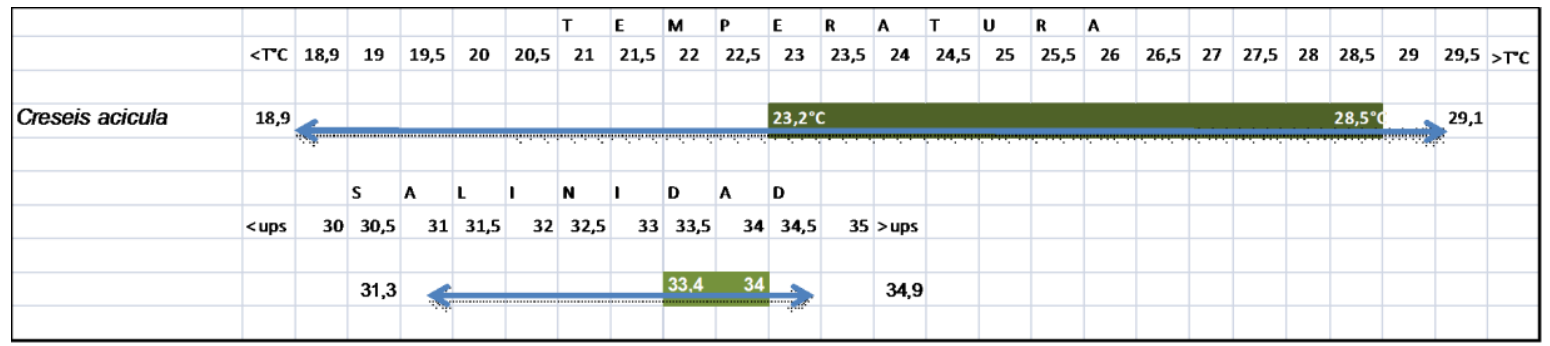

Fig. 10.- Rangos de tolerancia y preferencia de la temperatura y salinidad de Creseis acicula

Se han encontrado 554 ejemplares en 52 observaciones realizadas con una abundancia máxima de 92 ejemplares, considerándose como una especie Frecuente.

En el diagrama T-S (Fig. 11), se observa que Creseis acicula tiene preferencia por las aguas mayores a $23^{\circ} \mathrm{C}$, que incluyen las Aguas Ecuatoriales Superficiales (AES) y Aguas
Tropicales Superficiales (ATS). Su mayor abundancia se la encontró en Aguas Ecuatoriales Superficiales (AES) en agosto de 1993 cuando en la región 3.4 había un episodio neutral y en la región $1+2$ anomalías positivas de $0.27^{\circ} \mathrm{C}$ después de haberse presentado un evento El Niño.
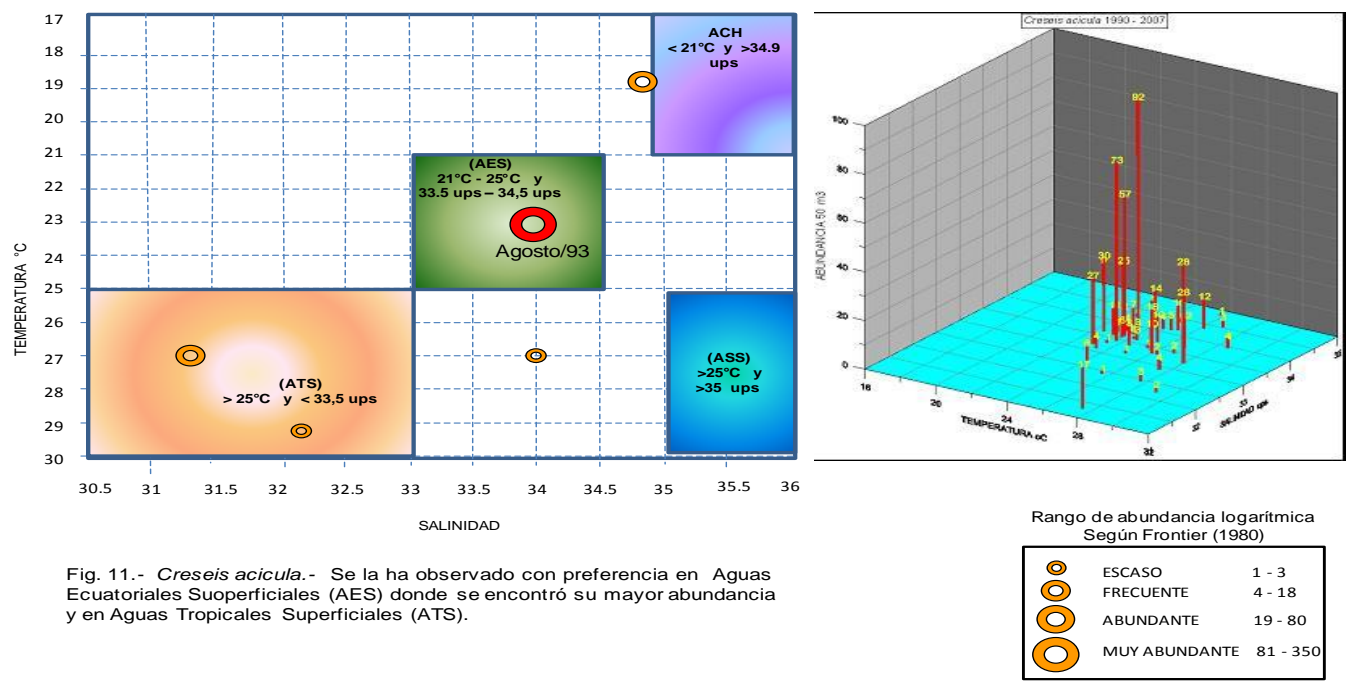

Fig. 11.- Creseis acicula.- Se la ha observado con preferencia en Aguas Ecuatoriales Suoperficiales (AES) donde se encontró su mayor abundancia y en Aguas Tropicales Superficiales (ATS). 
Observaciones: Creseis acicula es una especie que está relacionada con aguas cálidas y oceánicas, los juveniles son oceánicos y los adultos se reproducen en el talud continental (Frontier, 1973), se ha presentado en la estación fija de La Libertad, durante El Niño 1991-1992 y en 1993 cuando hubo un evento cálido en la región 1+2, también cuando se presentó El Niño 1997-1998. La presencia en la estación de La Libertad indica una intrusión de aguas cálidas oceánicas frente a la costa del Ecuador. Es considerada un buen indicador, cuando se asocia a otras especies de aguas cálidas como Hyalocylis striata, indica la presencia de aguas oceánicas cálidas.

\section{Familia CAVOLINIIDAE Creseis vírgula Rang, 1828)}

Conchilla recta que aumenta su diámetro hacia el lado anterior, no hay opérculo, para nadar utiliza el pie transformado en dos aletas llamados parapodios que se localizan en la parte dorsal a la boca (Spoel, V. y E. Boltovskoy 1981). Su ángulo varía desde los $30^{\circ}$ a $40^{\circ}$ (Tokioka, 1955). Es una especie oceánica que tolera las aguas neríticas de la Plataforma continental (Frontier, 1973). Es una especie típicamente tropical que no tiene ciclo nictimeral (Frontier, 1955). (Foto 4). En el mar ecuatoriano se la considera como una especie euriterma y eurihalina

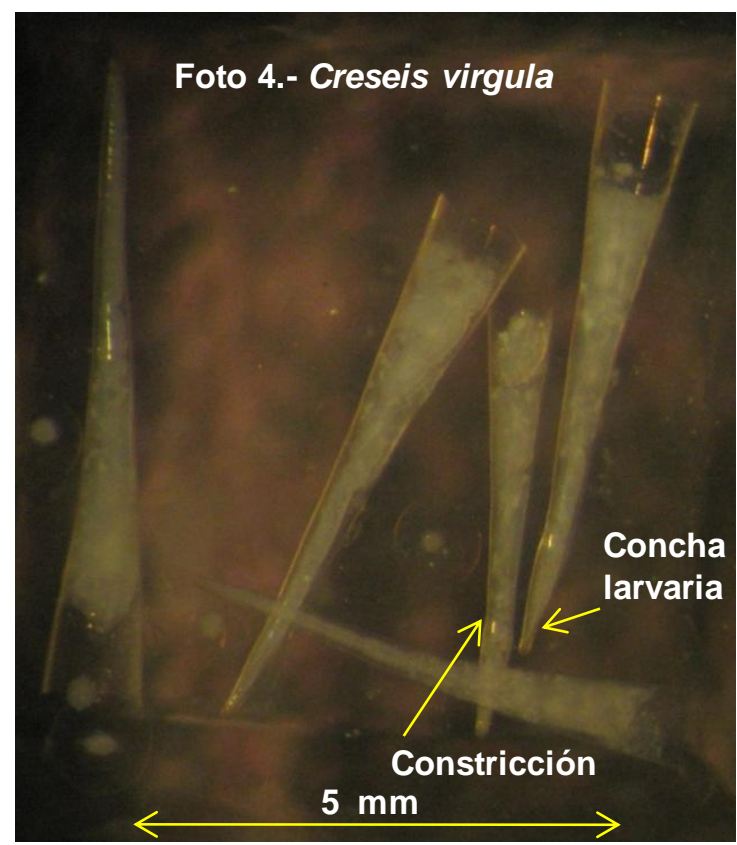

Creseis virgula se ha presentado en temperaturas de $18.9^{\circ} \mathrm{C}$ a $29.1^{\circ} \mathrm{C}$ con preferencia entre $22.6^{\circ} \mathrm{C}$ a $26^{\circ} \mathrm{C}$ y en salinidades de 30.1 ups a 34.3 ups, con preferencia de 32.7 ups a 34.3 ups (Fig. 12).

Se han encontrado 3388 ejemplares en 340 observaciones realizadas con una abundancia máxima de más de 400 ejemplares, considerándose como una especie frecuente y a veces se presenta muy abundante.

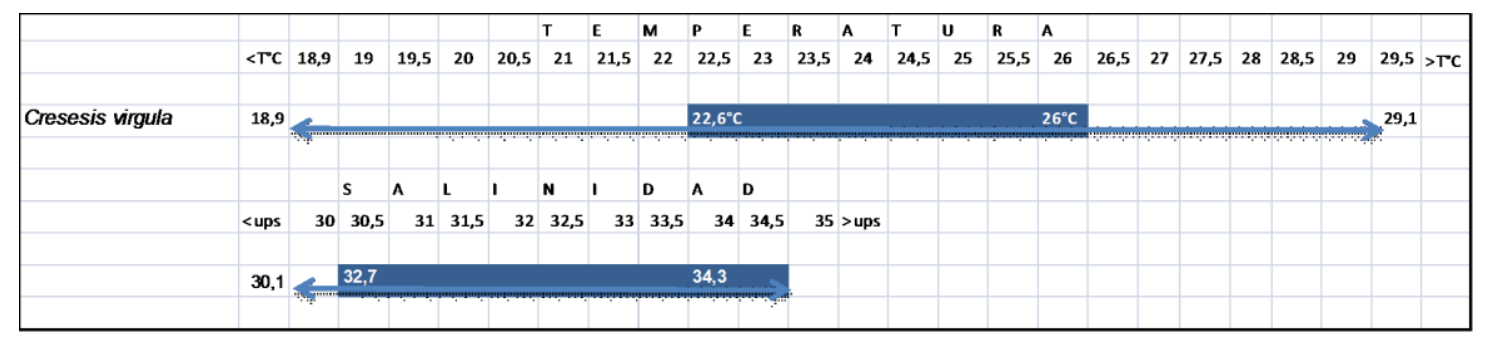

Fig. 12.- Rangos de tolerancia y preferencia de la temperatura y salinidad de Creseis virgula

En el diagrama T-S se observa que Creseis virgula tiene preferencia por las aguas mayores a $25^{\circ} \mathrm{C}$, que incluyen las Aguas Tropicales Superficiales (ATS) y masas de aguas mezcladas de (ATS) Aguas Subtropicales Superficiales (ASS). Su mayor abundancia se la encontró en estas aguas mezcladas (ATS) y (ASS) en febrero de 1994 (Fig. 13), cuando en la región 3.4 había un episodio neutral y en la región $1+2$ anomalías negativas de $-0.18^{\circ} \mathrm{C}$ antes de un evento La Niña. 


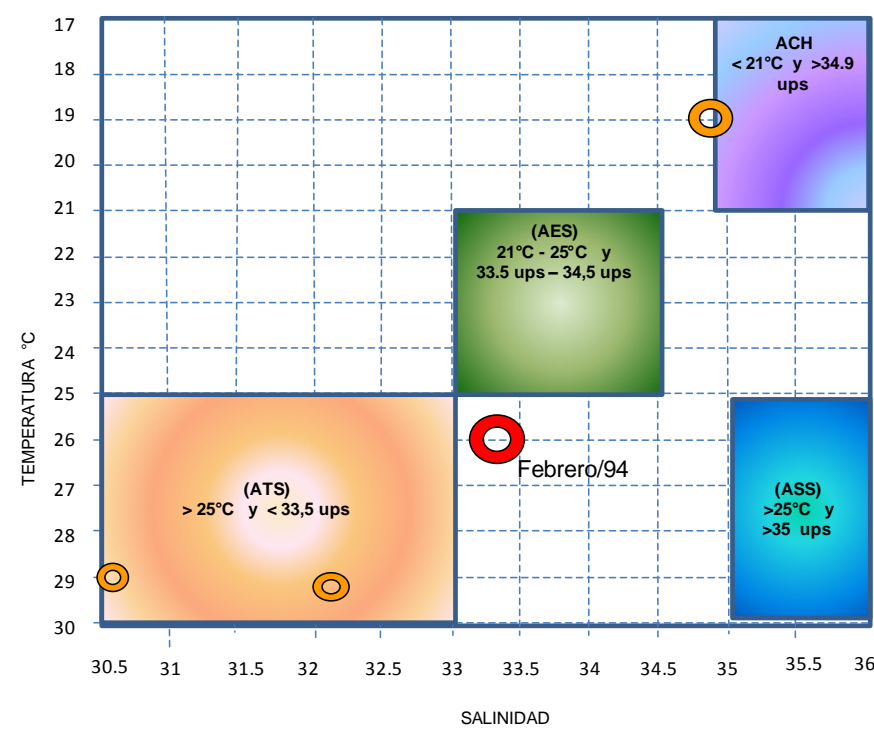

Fig. 13.- Creseis virgula.- Se observa que tiene una preferencia por las Aguas Cálidas y Oceánicas

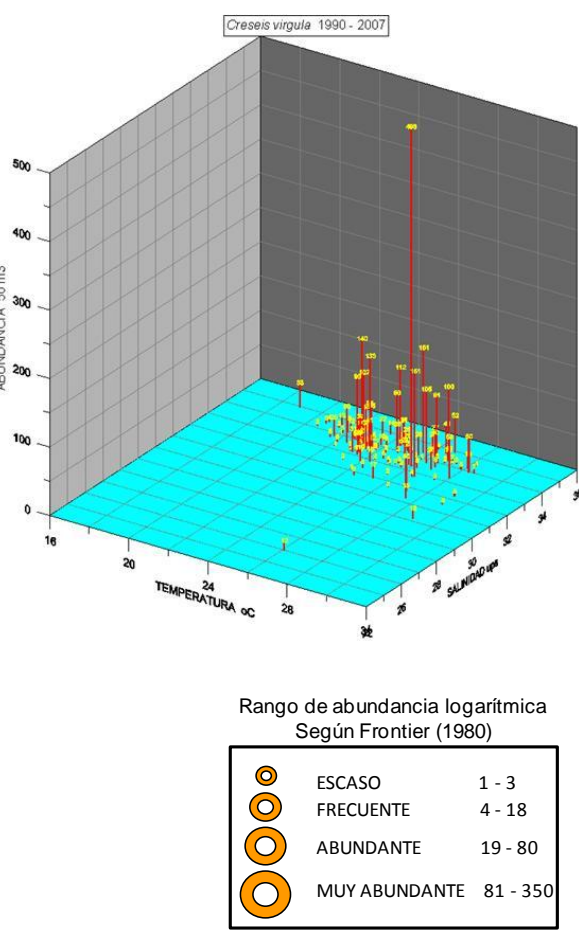

pequeñas (Spoel, 1972). Esta especie es oceánica y de aguas cálidas.

En el presente estudio se la considera estenoterma y eurihalina.

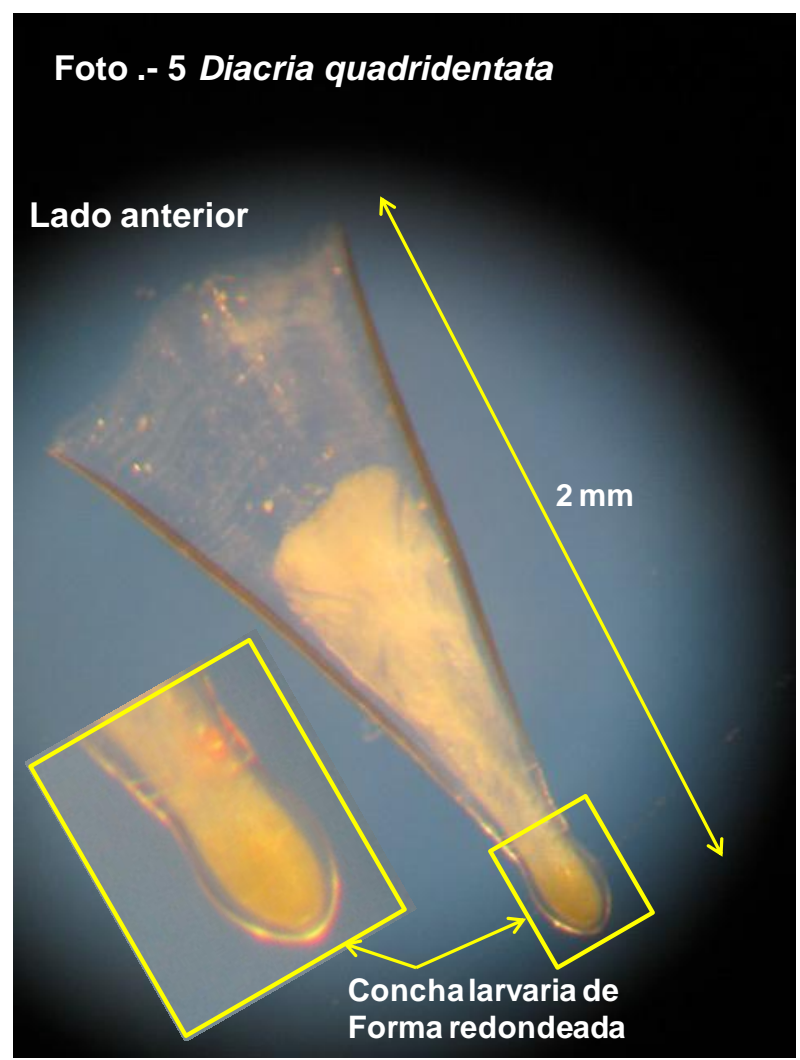


Diacria quadridentata se ha presentado en temperaturas de $23^{\circ} \mathrm{C}$ a $27.5^{\circ} \mathrm{C}$ con preferencia entre $23.3^{\circ} \mathrm{C}$ a $25.2^{\circ} \mathrm{C}$ y en salinidades de 31.9 ups a 34.9 ups, con preferencia de 31.9 ups a 34.9 ups (Fig. 14).

Se han encontrado 7 ejemplares en 6 observaciones realizadas con una abundancia máxima de 2 ejemplares, considerándose a esta especie rara.

En el diagrama T-S se observa que Diacria quadridentata tiene tendencia por las aguas mayores a $23^{\circ} \mathrm{C}$, que incluyen las Aguas Tropicales Superficiales (ATS) y masas de aguas mezcladas de (ATS) y Aguas Subtropicales Superficiales (ASS).

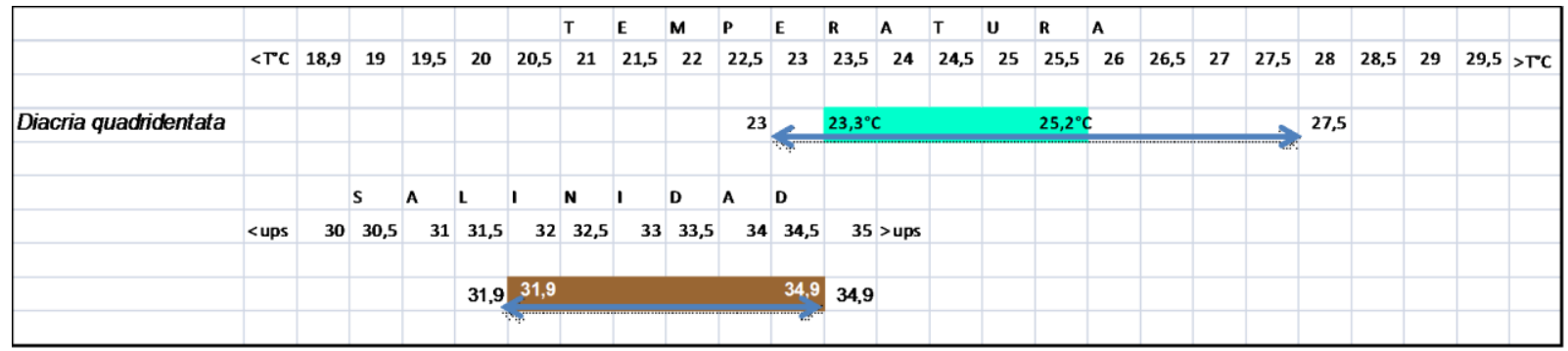

Fig. 14.- Rangos de tolerancia y preferencia de la temperatura y salinidad de Diacria quadridentata

Su mayor abundancia se la encontró en (ATS) en julio de 1995 (Fig. 15), cuando en la región 3.4 habían anomalías negativas y en la región $1+2$ estaba presente La Niña con anomalías de $-0.57^{\circ} \mathrm{C}$.

Observaciones: Diacria quadridentata es una especie rara, oceánica, se presentó antes de El
Niño 1991-1992, en julio de 1995, cuando hay anomalías cálidas, se ausenta en los eventos fríos de La Niña y no se la observó en El Niño 1997-1998. Es una especie que indica períodos de transición, su presencia minimiza la presencia de un evento como El Niño y La Niña.

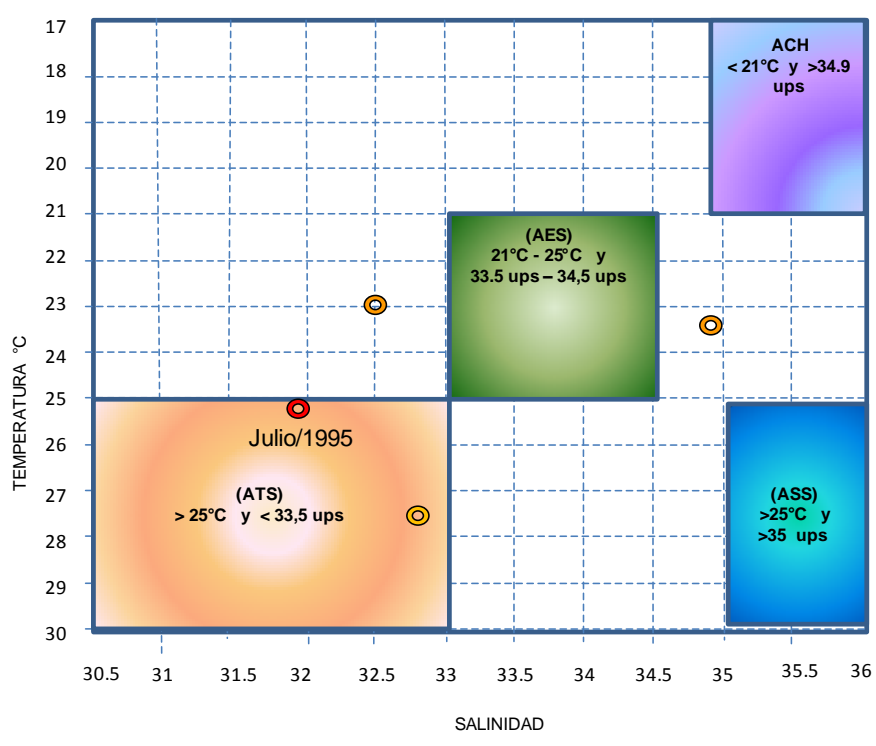

Fig. 15.- Diacria quadridentata.- Se observa una preferencia por las aguas Cálidas mayores a $23^{\circ} \mathrm{C}$ y las Aguas Tropicales Superficiales (ATS).

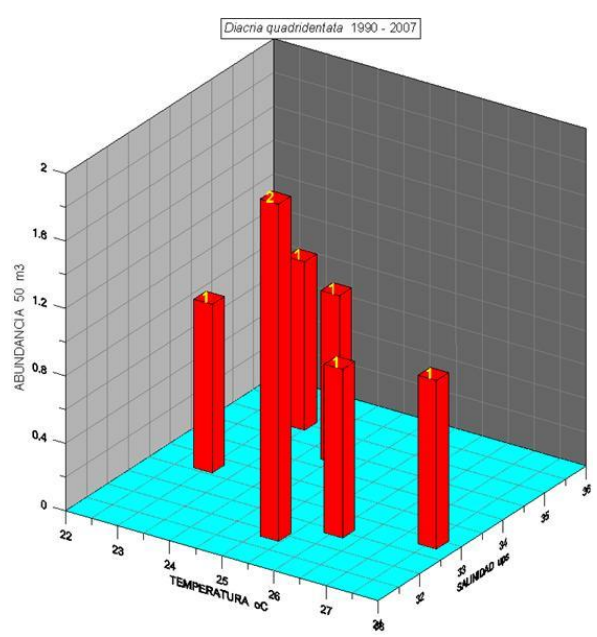

Rango de abundancia logarítmica Según Frontier (1980)

\begin{tabular}{|lll|}
\hline (2) & ESCASO & $1-3$ \\
() & FRECUENTE & $4-18$ \\
() & ABUNDANTE & $19-80$ \\
(1) & MUY ABUNDANTE & $81-350$ \\
\hline
\end{tabular}




\section{Familia CAVOLINIIDAE Hyalocylis striata (Rang, 1828)}

Concha de forma cónica, con una constricción que separa la concha adulta de la larvaria, que tiene forma ovalada, no puntudo (Rottman, 1976), se la reconoce fácilmente por presentar anulaciones o estrías transversales a lo largo de su concha, la que es transparente y frágil. Es una especie oceánica (Frontier, 1973), típicamente tropical (Tesch, 1948) y cosmopolita (Spoel y Boltovskoy 1981), su ángulo es ligeramente mayor que el de Creseis vírgula (foto 6).

En este estudio se la considera estenoterma y eurihalina.

Hyalocylis striata se ha presentado en temperaturas de $21.9^{\circ} \mathrm{C}$ a $29.1^{\circ} \mathrm{C}$ con

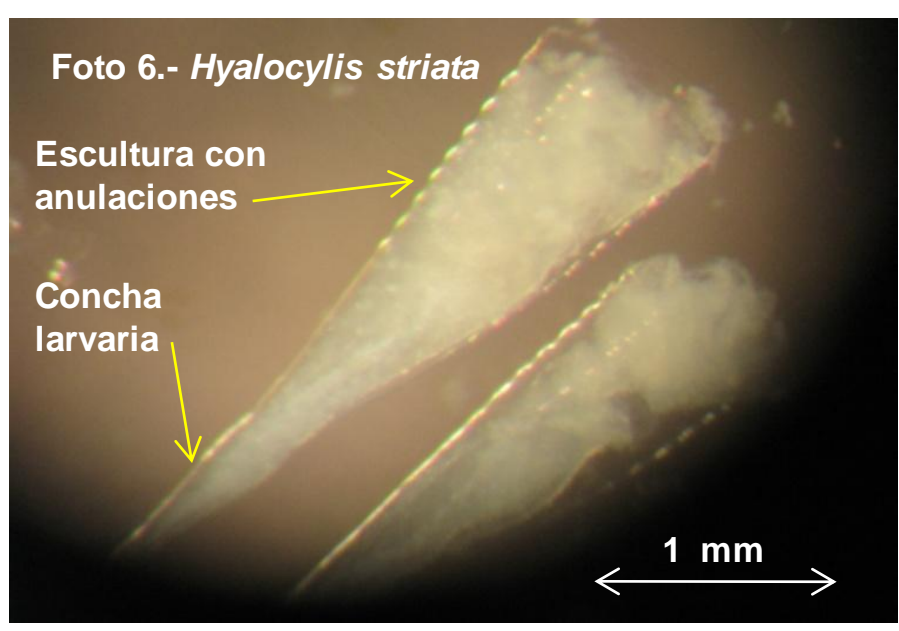

preferencia entre $26^{\circ} \mathrm{C}$ a $28.8^{\circ} \mathrm{C}$ y en salinidades de 30.1 ups a 34.8 ups, con preferencia de 30.1 ups a 33.3 ups (Fig. 16)

Se han encontrado 801 ejemplares en 51 observaciones realizadas con una abundancia máxima de 140 ejemplares, considerándose a esta especie como frecuente.

\begin{tabular}{|c|c|c|c|c|c|c|c|c|c|c|c|c|c|c|c|c|c|c|c|c|c|c|c|c|c|}
\hline & & & & & & & $T$ & E & M & P & E & $R$ & A & $\mathrm{T}$ & U & R & A & & & & & & & & \\
\hline & $<T C$ & 18,9 & 19 & 19,5 & 20 & 20,5 & 21 & 21,5 & 22 & 22,5 & 23 & 23,5 & 24 & 24,5 & 25 & 25,5 & 26 & 26,5 & 27 & 27,5 & 28 & 28,5 & 29 & 29,5 & $>T C$ \\
\hline \multirow{7}{*}{ Hyalocylis striata } & & & & & & & 219 & & & & & & & & & & $26^{\circ} \mathrm{C}$ & & & & & & & & \\
\hline & & & & & & & & & 4 & & & & & & & & & & & & & & & & \\
\hline & & & $s$ & A & L & I & $\mathbf{N}$ & 1 & D & A & D & & & & & & & & & & & & & & \\
\hline & < ups & 30 & 30,5 & 31 & 31,5 & 32 & 32,5 & 33 & 33,5 & 34 & 34,5 & 35 & $>$ ups & & & & & & & & & & & & \\
\hline & & & & & & & & & & & & & & & & & & & & & & & & & \\
\hline & 30,1 & & 30,1 & & & & & & 33,3 & & & & 34,8 & & & & & & & & & & & & \\
\hline & & & & & & & & & & & & & & & & & & & & & & & & & \\
\hline
\end{tabular}

Fig. 16.- Rangos de tolerancia y preferencia de la temperatura y salinidad de Hyalocylis striata

En el diagrama T-S se observa que Hyalocylis striata tiene tendencia por las aguas cálidas mayores a $25^{\circ} \mathrm{C}$, que incluyen las Aguas Tropicales Superficiales (ATS) y Aguas Subtropicales Superficiales (ASS) que generalmente están relacionadas con los eventos calientes como El Niño. Su mayor abundancia se la encontró en febrero de 1994 cuando en la región $1+2$ habían anomalías negativas y en junio de 1998 cuando en todo el océano Pacífico estaba el evento El Niño (Fig. 17) 

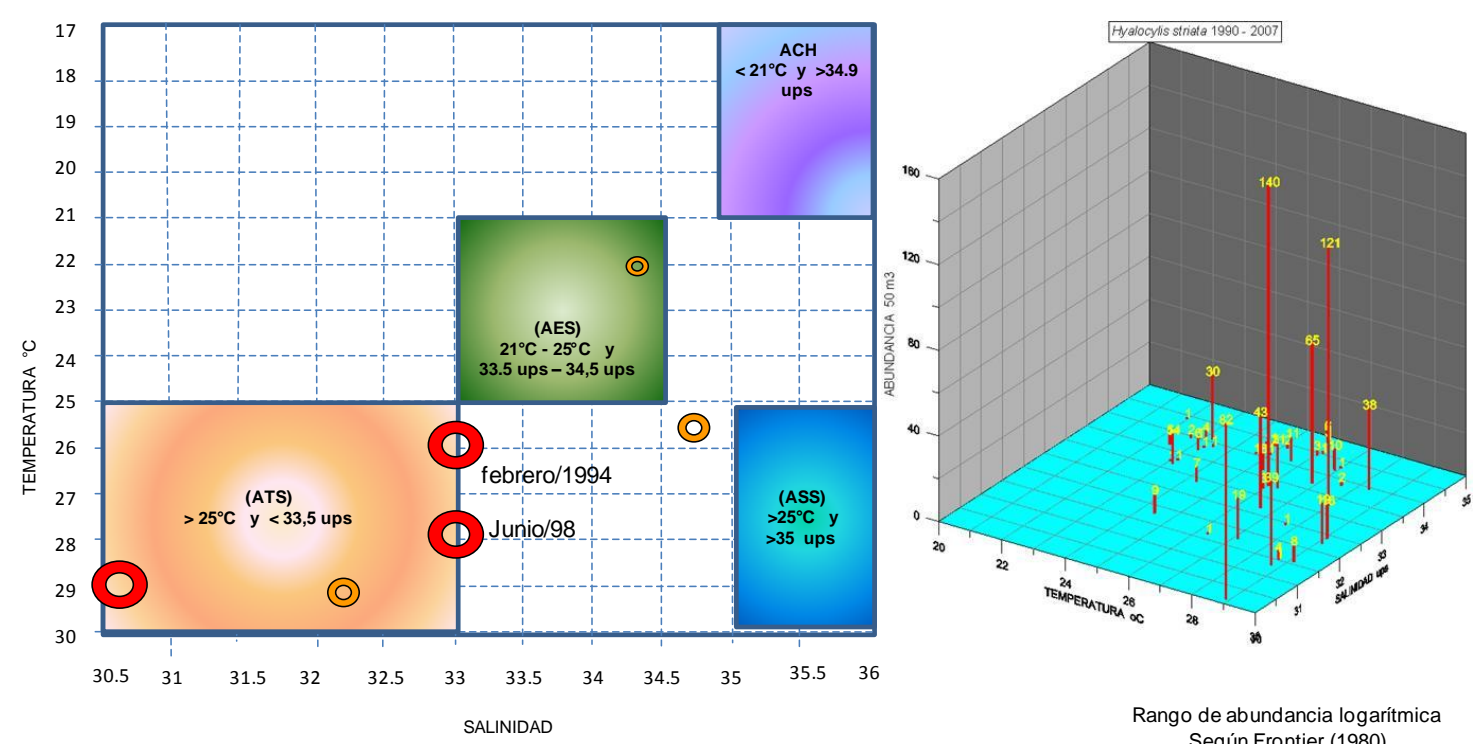

Fig. 17.- Hyalocylis striata. Se observa una preferencia por las Aguas

Tropicales Superficiales (ATS) mezcladas con Aguas Subtropicales Superficiales (ASS)

Rango de abundancia logarítmica Según Frontier (1980)

\begin{tabular}{|lll|}
\hline (2) & ESCASO & $1-3$ \\
()) & FRECUENTE & $4-18$ \\
() & ABUNDANTE & $19-80$ \\
(O) & MUY ABUNDANTE & $81-350$ \\
\hline
\end{tabular}

Observaciones: Hyalocylis striata. presenta una preferencia por las aguas calientes entre los $26^{\circ}$ a más de $28^{\circ} \mathrm{C}$, es de ambiente oceánico y en la estación fija de La Libertad se ha presentado de forma abundante cuando hay un evento El Niño. El desarrollo de su concha está relacionada con la madurez del evento, es decir, que cuando son juveniles hay ligeras influencias de aguas oceánicas cálidas y las anomalías positivas son menores a $1^{\circ} \mathrm{C}$, pero cuando su conchilla está desarrollada y su abundancia es relevante, el evento El Niño está presente con anomalías cálidas de más de $1.5^{\circ} \mathrm{C}$ y la temperatura del mar es superior a $27^{\circ} \mathrm{C}$. Esta especie es considerada como un excelente indicador de aguas cálidas y el evento El Niño.

\section{Familia DESMOPTERIDAE Desmopterus papilio Chun, 1819}

Esta especie de pterópodo pseudotecosomado posee una concha cartilaginosa, que generalmente la pierden, por eso es muy común encontrar en una muestra de plancton solo al organismo, que tiene forma ovalada cuando sus parapodios están extendidos y son más grandes que su cuerpo o masa visceral, la parte posterior tiene cinco lóbulos muy visibles y fácil de reconocerlos. Según Frontier (1963) su distribución es irregular en el océano Indico, que varió desde 1 a 79 individuos. Esta especie es fácilmente reconocida por su musculatura fina en sus parapodios (foto 7), y se la diferencia de Desmopterus gardineri, que tiene musculatura gruesa. En este estudio se la ha considerado como estenoterma y estenohalina.

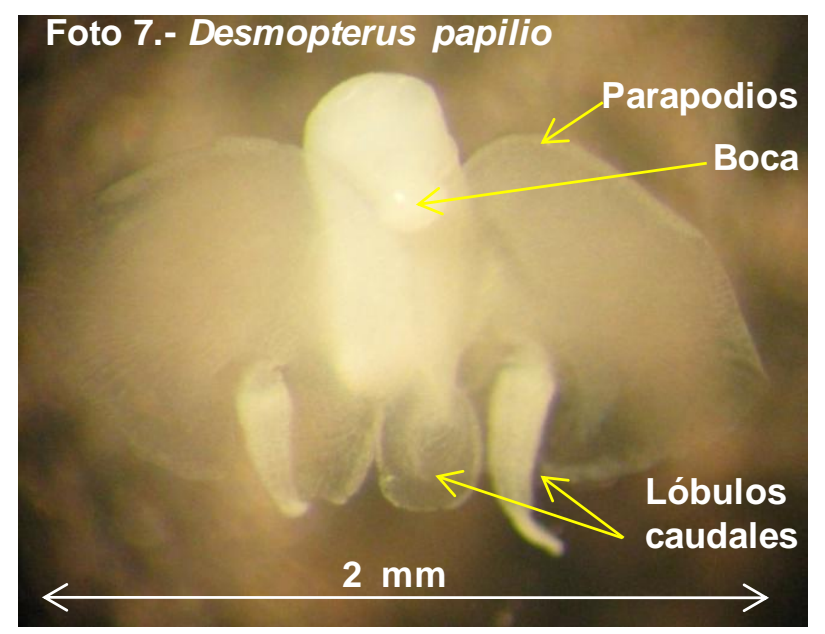

Desmopterus papilio se ha presentado en temperaturas de $22.4^{\circ} \mathrm{Ca} \quad 28.8^{\circ} \mathrm{C}$ con preferencia entre $24.5^{\circ} \mathrm{C}$ a $25.1^{\circ} \mathrm{C}$ y en 
salinidades de 30.1 ups a 34.8 ups, con preferencia de 34.1 ups a 34.5 ups (Fig. 18)

Se han encontrado 89 ejemplares en 14 observaciones realizadas con una abundancia máxima de 27 ejemplares, considerándose a esta especie como frecuente.
En el diagrama T-S se observa que Desmopterus papilio tiene tendencia por las aguas cálidas mayores a $24.5^{\circ} \mathrm{C}$, que incluyen las Aguas Ecuatoriales Superficiales (AES) y las Aguas Subtropicales Superficiales (ASS) por la preferencia de aguas de alta salinidad.

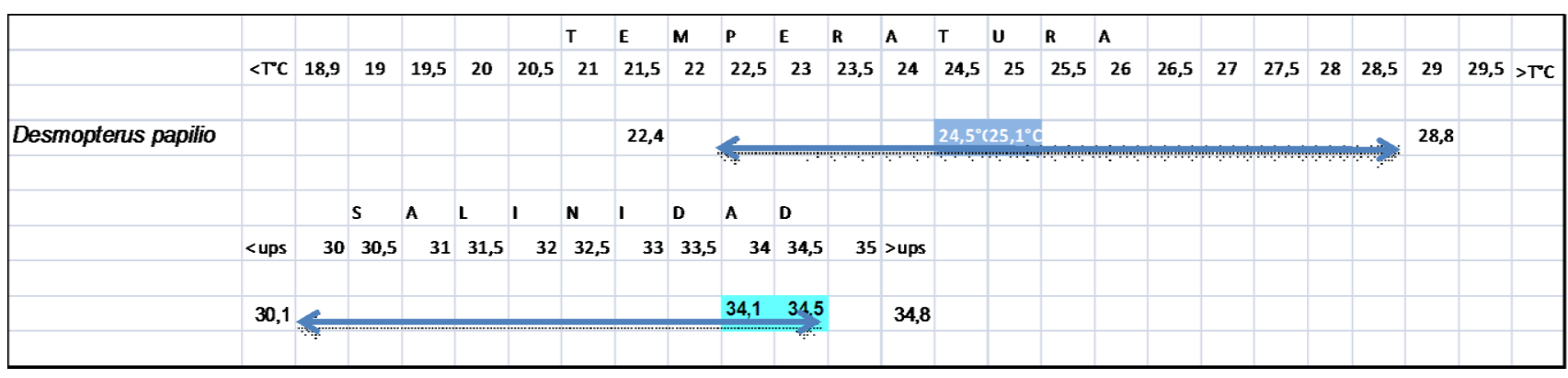

Fig. 18.- Rangos de tolerancia y preferencia de la temperatura y salinidad de Desmopterus papilio

Su mayor abundancia se la encontró en abril de 1994 cuando en la región niño 3.4 habían anomalías positivas y en la región niño $1+2$ estaba el evento frío de La Niña, mientras que en abril de 1997 está relacionada con anomalías positivas en el Pacífico central y el evento El Niño que se encontraba en la región niño $1+2$ (Fig. 19).

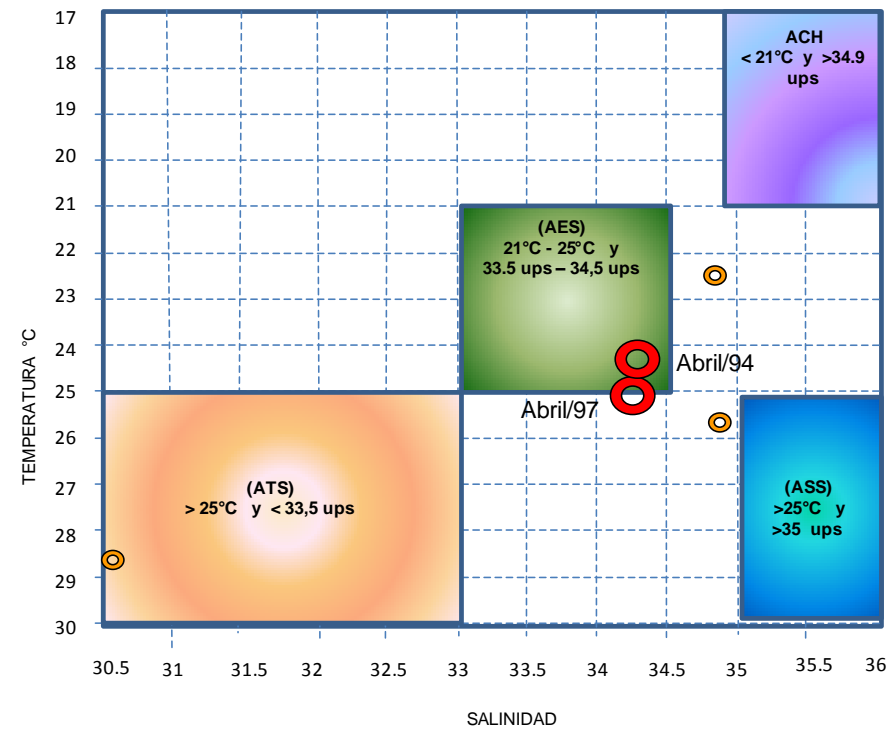

Fig. 19.- Desmopterus papilio. Se ha presentado en Aguas Ecuatoriales Supèrficiales (AES) mezcladas con Aguas Subtropicales Supoerficiales (ASS) Por sus preferencias a las altas salinidades

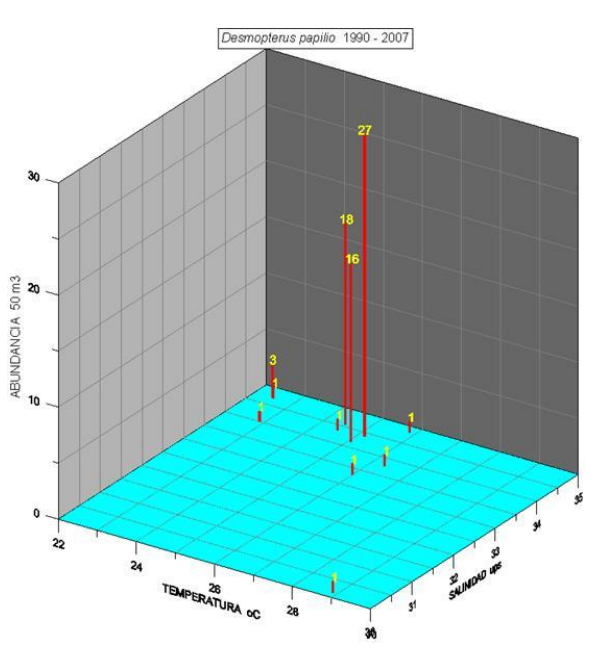

Rango de abundancia logarítmica Según Frontier (1980)

$\begin{array}{|lll|}\text { () } & \text { ESCASO } & 1-3 \\ \text { () } & \text { FRECUENTE } & 4-18 \\ \text { (O) } & \text { ABUNDANTE } & 19-80 \\ \text { (1) } & \text { MUY ABUNDANTE } & 81-350\end{array}$


Observaciones: Esta especie de ambiente oceánico, es considerada de escasa a frecuente por su abundancia y densidad variable, se ha presentado en la estación fija de La Libertad en 1993 cuando en la región 1+2 había fuertes anomalías cálidas y durante El Niño 19971998, que representó el $1.6 \%$ (Cruz, 20052006) y aunque es una especie poco abundante, su presencia está relacionada con anomalías cálidas.

\section{Familia LIMACINIDAE \\ Limacina bulimoides (Orbigny, 1836)}

Concha pequeña transparente de forma trochiforme, levógira con opérculo de constitución quitinosa, escultura lisa, pie en forma de aletas denominados parapodios, espira de la concha más alta que ancha con aproximadamente 5 anfractos o vueltas no apretados, escultura lisa (foto 8).
Esta especie en el presente estudio se la considera estenoterma y estenohalina Limacina bulimoides, se ha presentado en temperaturas de $23^{\circ} \mathrm{C}$ a $26.1^{\circ} \mathrm{C}$ con preferencia entre $23.6^{\circ} \mathrm{C}$ a $23.7^{\circ} \mathrm{C}$ y en salinidades de 33.7 ups a 34.3 ups, con preferencia de 30.1 ups a 33.3 ups (Fig. 20).

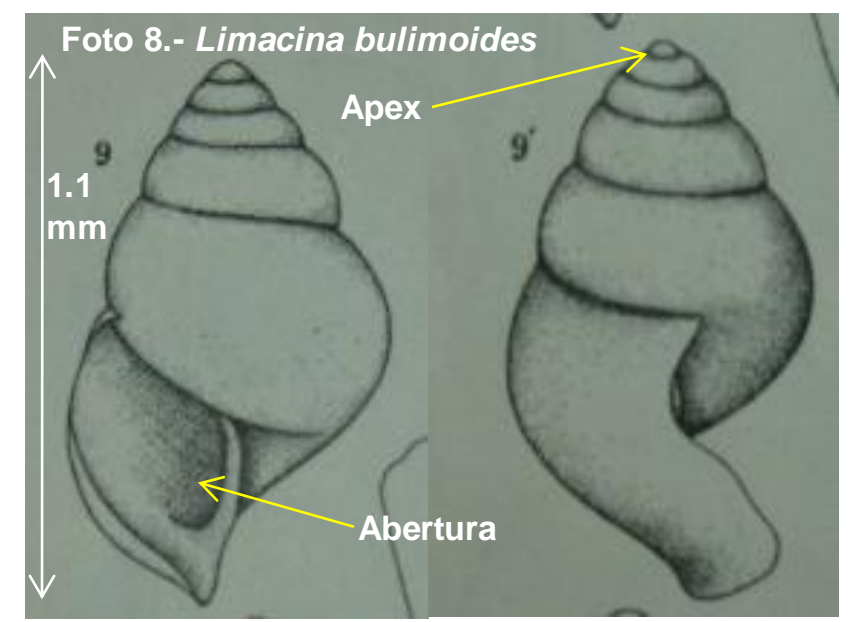

Foto 8.- Se observan las vueltas o espiras no apretadas (Tomado de: Tokioka, 1955)

\begin{tabular}{|c|c|c|c|c|c|c|c|c|c|c|c|c|c|c|c|c|c|c|c|c|c|c|c|c|c|}
\hline & & & & & & & $\mathbf{T}$ & E & $\mathbf{M}$ & $\mathbf{P}$ & E & $\mathbf{R}$ & A & $\mathbf{T}$ & v & $\mathbf{R}$ & A & & & & & & & & \\
\hline & $<T C$ & 18,9 & 19 & 19,5 & 20 & 20,5 & 21 & 21,5 & 22 & 22,5 & 23 & 23,5 & 24 & 24,5 & 25 & 25,5 & 26 & 26,5 & 27 & 27,5 & 28 & 28,5 & 29 & 29,5 & $>T^{\circ} \mathrm{C}$ \\
\hline \multirow[t]{6}{*}{ Limacina bulimoides } & & & & & & & & & & 23 & & \multicolumn{3}{|c|}{$23,6^{\circ} \mathrm{C}-23,7^{\circ} \mathrm{C}$} & & & & 26,1 & & & & & & & \\
\hline & & & & & & & & & & & 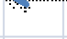 & & & & & & & & & & & & & & \\
\hline & & & $S$ & A & L & I & N & 1 & D & A & D & & & & & & & & & & & & & & \\
\hline & < ups & 30 & 30,5 & 31 & 31,5 & 32 & 32,5 & 33 & 33,5 & 34 & 34,5 & 35 & > ups & & & & & & & & & & & & \\
\hline & & & & & & & & 33,7 & & 33,7 & 34,3 & & 34,3 & & & & & & & & & & & & \\
\hline & & & & & & & & & & & & & & & & & & & & & & & & & \\
\hline
\end{tabular}

Fig. 20.- Rangos de tolerancia y preferencia de la temperatura y salinidad de Limacina bulimoides

Se han encontrado 7 ejemplares en 4 observaciones realizadas con una abundancia máxima de 3 ejemplares, considerándose a esta especie como rara.

En el diagrama T-S se observa que Limacina bulimoides tiene tendencia por las Aguas
Ecuatoriales Superficiales donde se encontró su máxima abundancia en octubre de 1993 (Fig. 21). Esta especie considerada rara, desde 1993, no se la ha vuelto a encontrar, es decir, hace 17 años. 


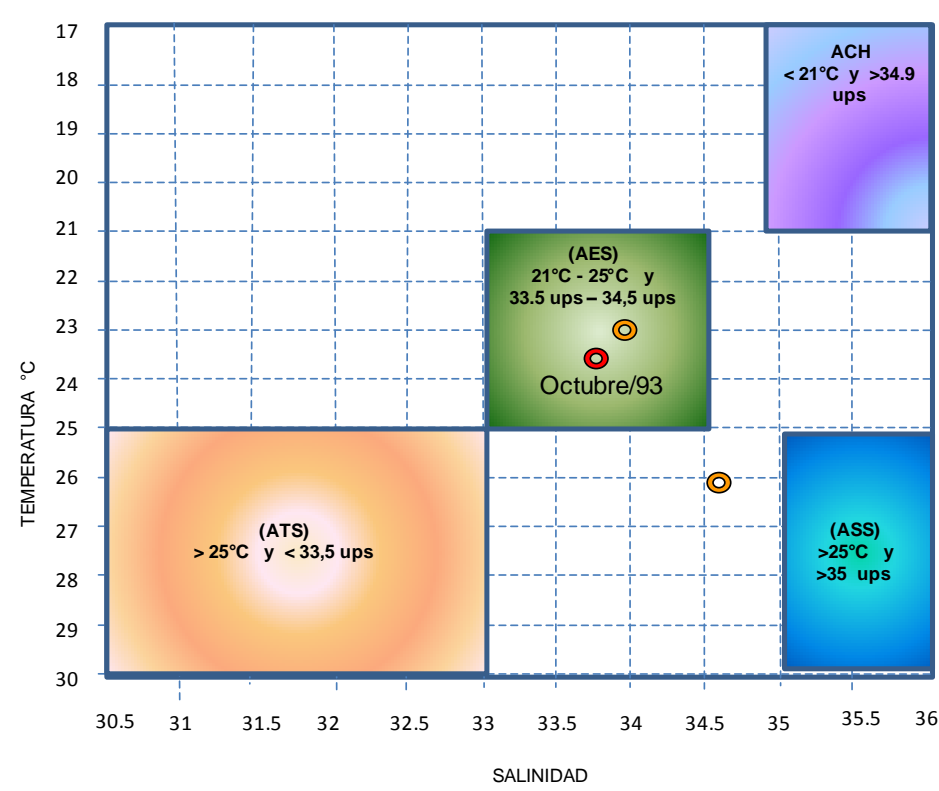

Fig. 21.- Limacina bulimoides. Se ha presentado en Aguas Ecuatoriales Superficiales (AES) y mezcladas con Aguas Subtropicales Superficiales (ASS)

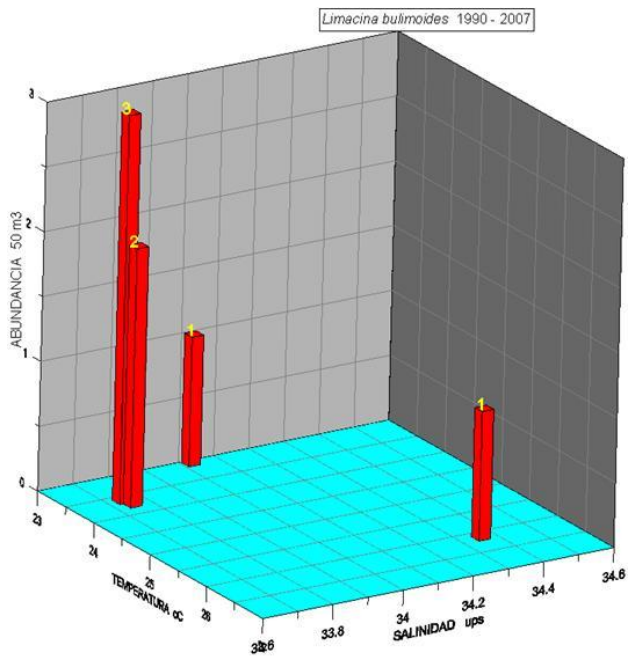

Rango de abundancia logarítmica Según Frontier (1980)

\begin{tabular}{|lll|}
\hline () & ESCASO & $1-3$ \\
() & FRECUENTE & $4-18$ \\
(O) & ABUNDANTE & $19-80$ \\
(O) MUY ABUNDANTE & $81-350$ \\
\hline
\end{tabular}

especie que se presentó durante los años 1992 y 1993, con preferencia por Aguas Ecuatoriales Superficiales (AES), cuando habían anomalías positivas en la estación fija La Libertad. No se la ha vuelto a ver hasta la fecha $y$ se desconocen las razones.

\section{Familia LIMACINIDAE}

\section{Limacina trochiformis (Orbigny, 1836)}

Concha pequeña, de forma trochiforme, más globosa que Limacina bulimoides, es tan alta como ancha con 5 a 6 vueltas o anfractos apretados, las suturas son de color café claro, levógira, con un pequeño ombligo, abertura redondeada con el labio externo de color lila claro a ligeramente púrpura-café, con opérculo quitinoso transparente, pie en forma de dos aletas o parapodios (foto 9).

En este estudio se la ha considerado como euriterma y estenohalina frente a la costa ecuatoriana.

\section{Foto 9.- Limacina trochiformis}

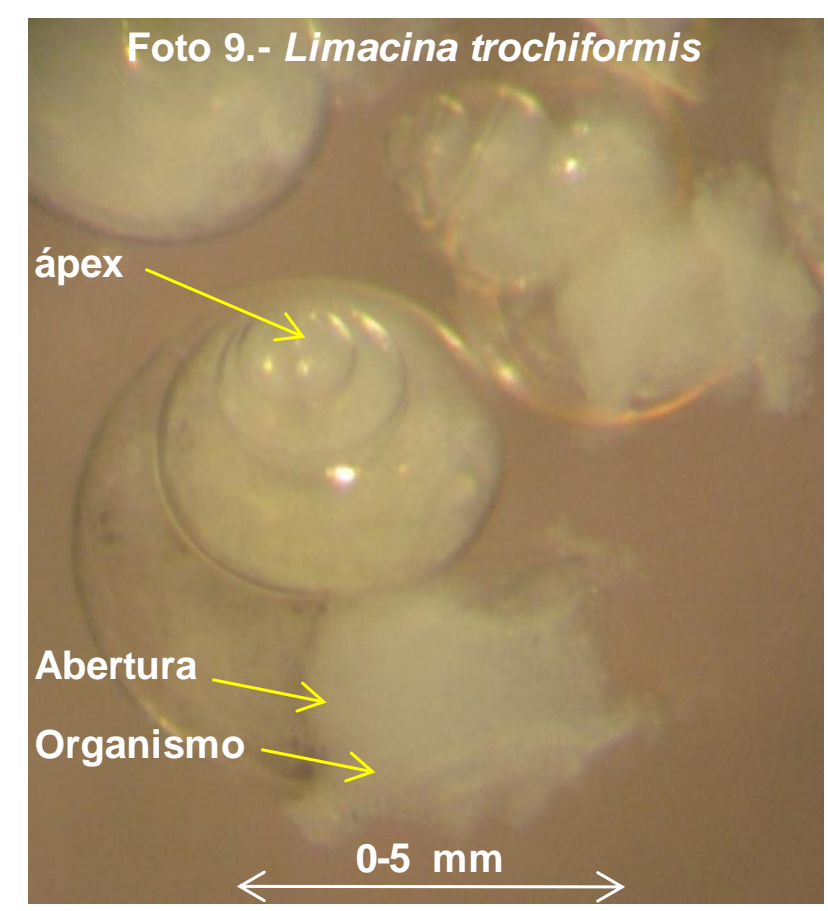

Limacina trochiformis se ha presentado en temperaturas de $20.7^{\circ} \mathrm{C}$ a $29.1^{\circ} \mathrm{C}$ con preferencia entre $23.6^{\circ} \mathrm{C}$ a $27.7^{\circ} \mathrm{C}$ y en salinidades de 31.6 ups a 34.8 ups, con preferencia de 32.4 ups a 33.8 ups (Fig. 22) 


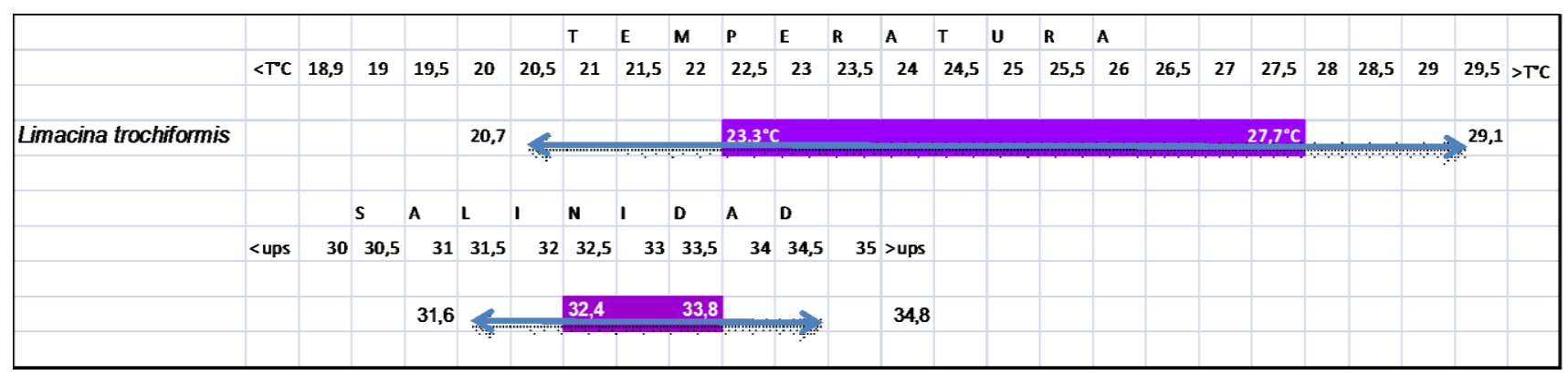

Fig. 22.- Rangos de tolerancia y preferencia de la temperatura y salinidad de Limacina trochiformis

Se encontraron 1093 ejemplares en 115 observaciones realizadas con una abundancia máxima de 110 ejemplares, considerándose a esta especie como frecuente.

En el diagrama T-S se observa que Limacina trochiformis tiene tendencia por las aguas cálidas mayores a $23.3^{\circ} \mathrm{C}$, que incluyen las

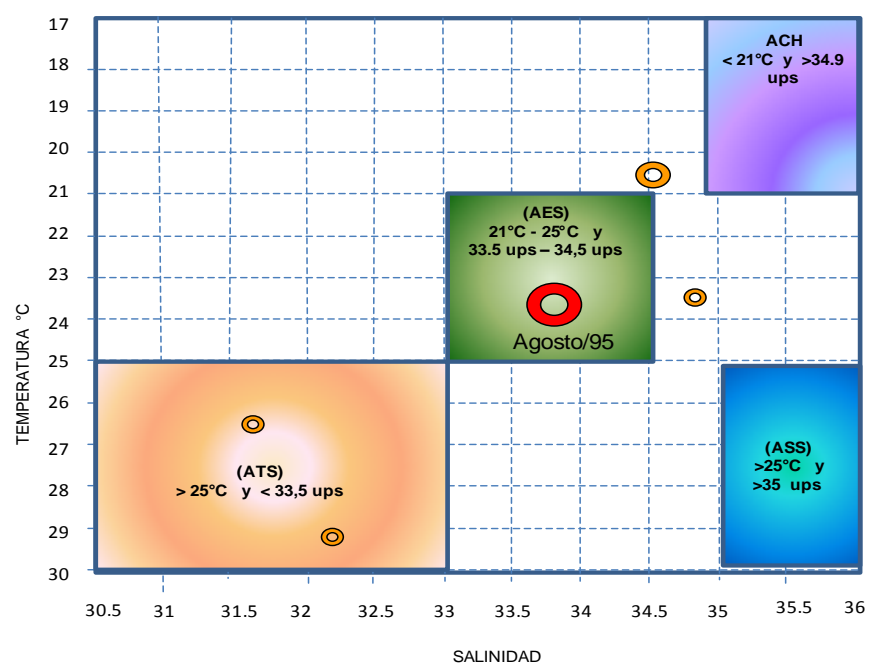

Fig. 23.- Limacina trochiformis. Se ha presentado conpreferencia por las Aguas Ecuatoriales Superficiales (AES) y Aguas Tropicales Superficiales (ATS)
Aguas Ecuatoriales Superficiales (AES) y las Aguas Tropicales Superficiales (ATS).

Su mayor abundancia se la encontró en agosto de 1995 cuando en la región niño 3.4 habían anomalías negativas de $-0.38^{\circ} \mathrm{C}$ y en la región niño $1+2$ estaba terminando el evento frío de La Niña (Fig. 23).

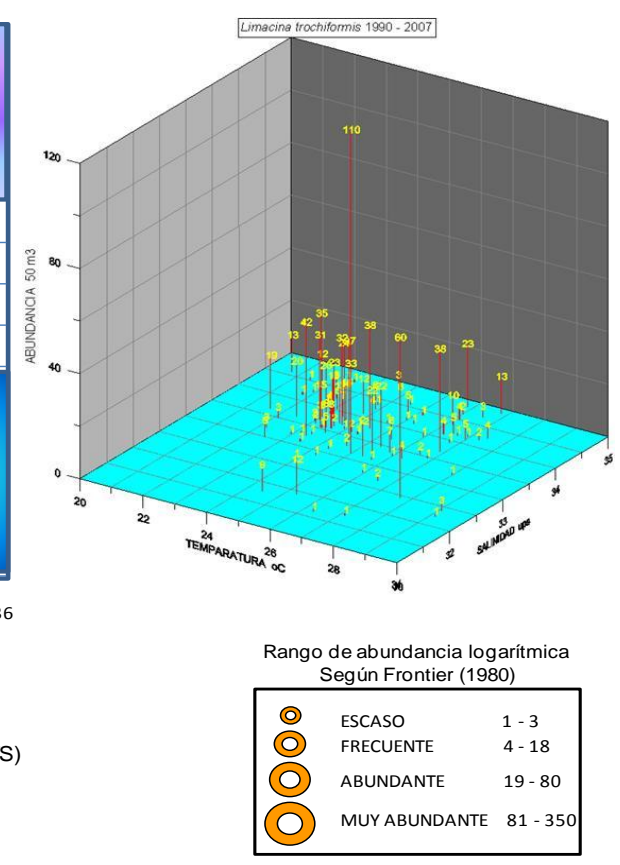

\section{Atlanta gaudichaudi Souleyet, 1852}

Familia ATLANTIDAE.- Concha calcárea presente, de forma planoespiral, comprimida lateralmente, con opérculo de constitución quitinosa, el organismos puede entrar totalmente dentro de su concha, pie modificado o con lóbulos adaptados para nadar.
Especie de ambiente oceánico, con 4.5 a 5.5 vueltas, espiras o anfractos, que aumentan progresivamente, la última vuelta es angosta y larga, la base de la carina es de color rojo-café. Del lado interno posee un ombligo profundo $y$ se cuentan de 3 a 3.5 vueltas (foto 10 ). 


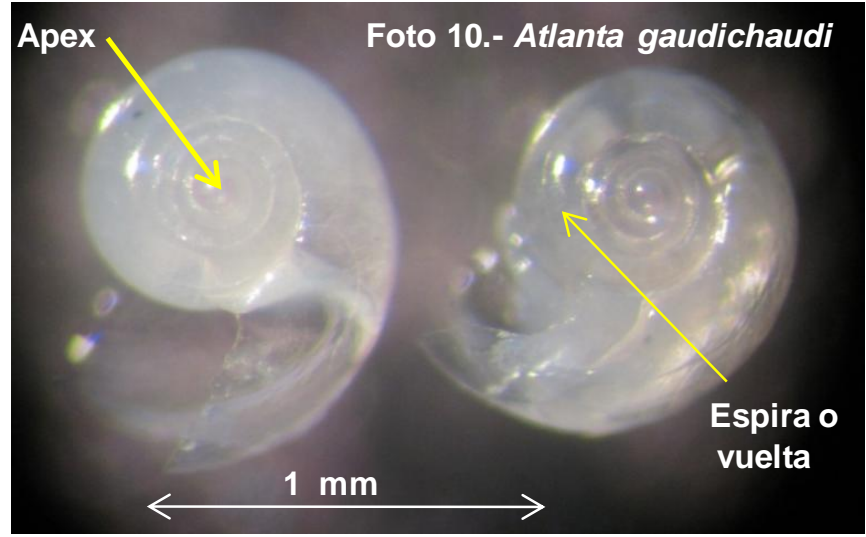

En este trabajo es considerada como una especie euriterma y eurihalina frente a la costa ecuatoriana.

Atlanta gaudichaudi se ha presentado en temperaturas de $20.7^{\circ} \mathrm{C}$ a $29.1^{\circ} \mathrm{C}$ con preferencia entre $25^{\circ} \mathrm{C}$ a $26.2^{\circ} \mathrm{C}$ y en salinidades de 31.2 ups a 34.9 ups, con preferencia de 32.6 ups a 34.1 ups (Fig. 24).

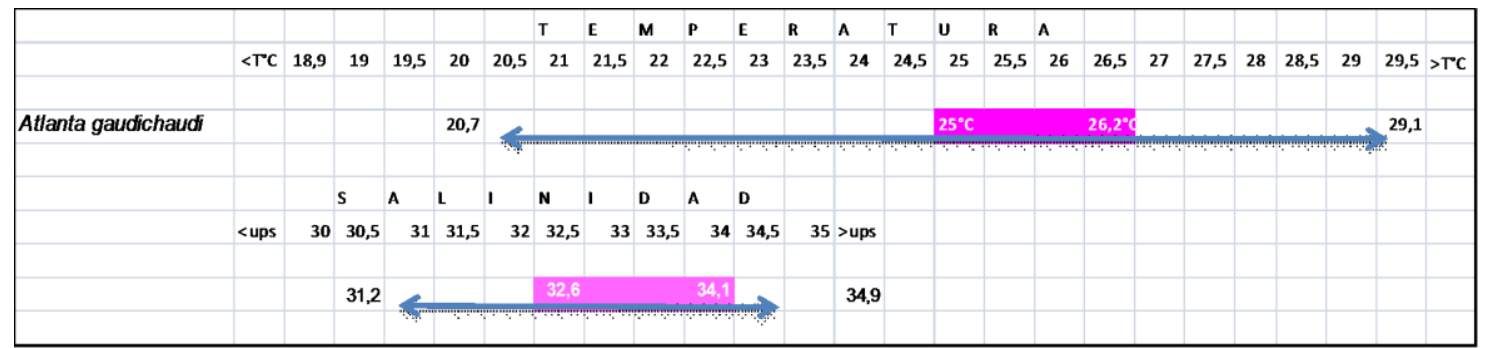

Fig. 24.- Rangos de tolerancia y preferencia de la temperatura y salinidad de Atlanta gaudichaudi

Se han encontrado 89 ejemplares en 14 observaciones realizadas con una abundancia máxima de 27 ejemplares, considerándose a esta especie como frecuente.

En el diagrama T-S se observa que Atlanta gaudichaudi tiene tendencia por las Aguas Tropicales Superficiales (ATS) y aguas mezcladas que pueden tener alta salinidad como las Aguas Subtropicales Superficiales (ASS).

Su mayor abundancia se la encontró en febrero del 2002 cuando en las regiones niño 3.4 y 1+2 habían anomalías positivas (Fig. 25).

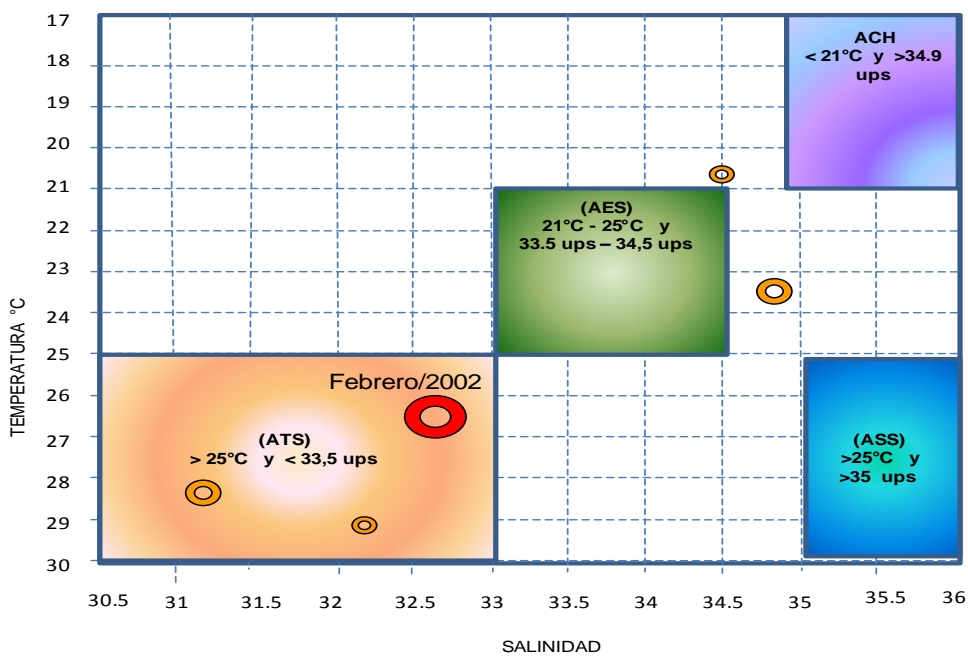

Fig. 25.- Atlantagaudichaudi. Se ha presentado en Aguas Tropicales Superficiales (ATS) y mezcladas con masas de aguas de alta salinidad

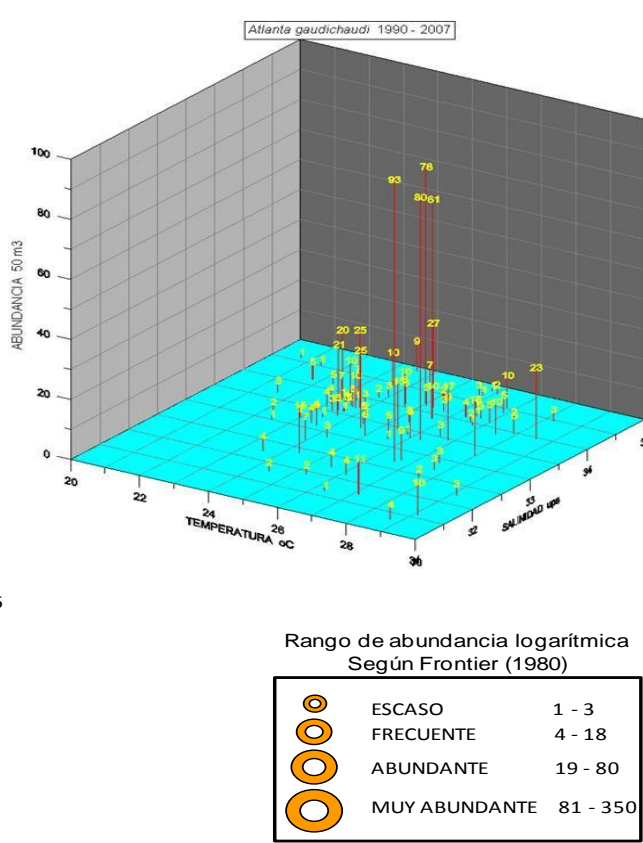


Observaciones: En la estación fija La Libertad se la ha observado rara veces antes de El Niño 1991-1992, pero en abril de 1993 su abundancia aumentó de manera significativa, siempre se ha presentado cuando hay anomalías positivas y durante El Niño 1997-1998 estuvo muy frecuente.

Se ha observado que hay una ligera relación con Atlanta peroni, coincidiendo con lo mencionado por Tesch, 1948. Cuando hay un evento frío, puede presentarse poco abundante y ausentarse también.

\section{ATLANTIDAE \\ Atlanta lesueuri Souleyet 1852}

Conchilla dextrógira con 3.5 vueltas o anfractos, la última vuelta es relativamente ancha como también su abertura de forma ovalada, la carina puede insertarse hasta la penúltima vuelta y el ángulo de la espira es de aproximadamente $140^{\circ}$ (Frontier, 1966) (foto 11).

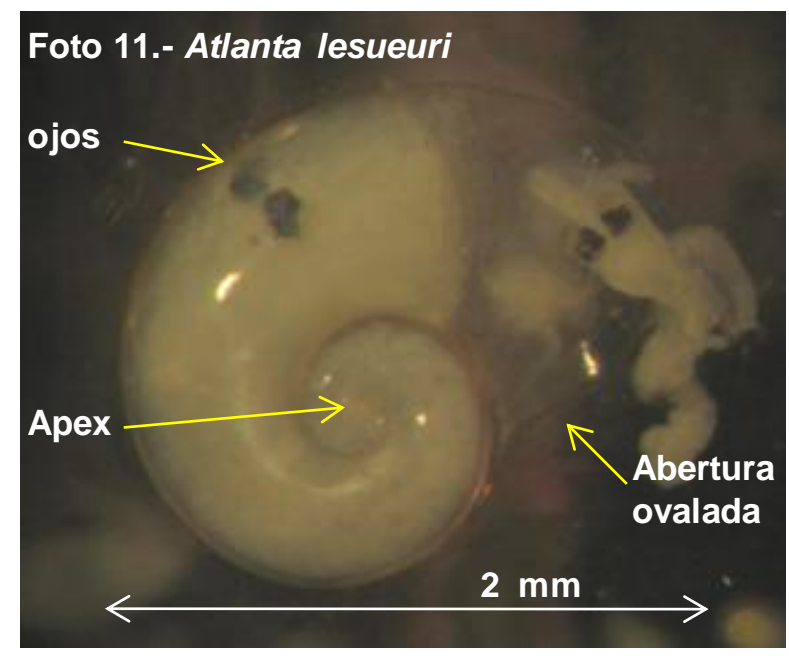

Esta especie es considerada como euriterma y eurihalina en el océano Pacífico oriental, frente a la costa ecuatoriana.

Atlanta lesueuri se ha presentado en temperaturas de $18.9^{\circ} \mathrm{C}$ a $29.1^{\circ} \mathrm{C}$ con preferencia entre $23^{\circ} \mathrm{C}$ a $27^{\circ} \mathrm{C}$ y en salinidades de 30.1 ups a 34.9 ups, con preferencia de 31.3 ups a 33.7 ups (Fig. 26).

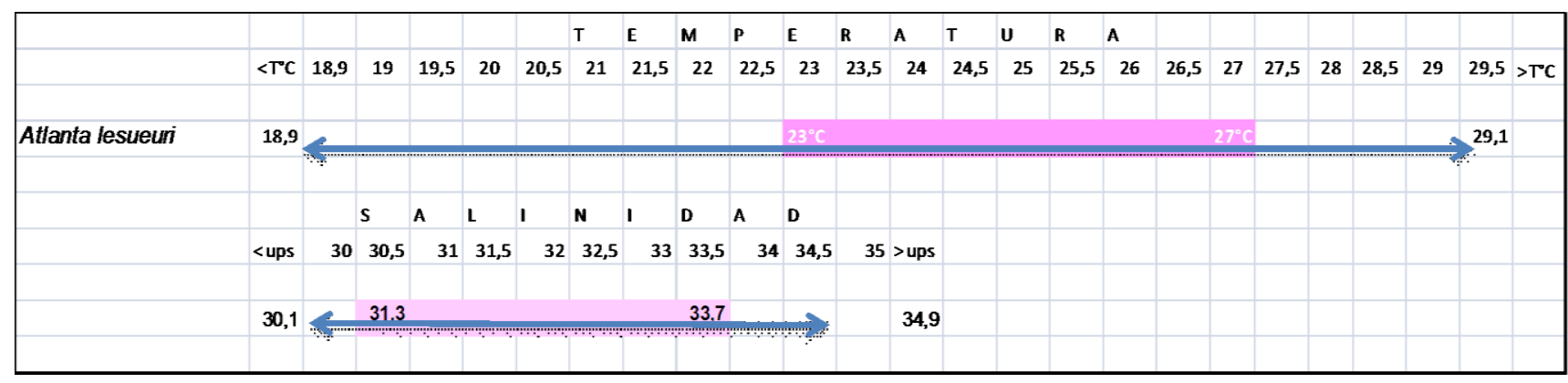

Fig. 26.- Rangos de tolerancia y preferencia de la temperatura y salinidad de Atlanta lesueuri

Se han encontrado 270 ejemplares en 79 observaciones realizadas con una abundancia máxima de 24 ejemplares, considerándose a esta especie como rara a frecuente.

En el diagrama T-S se observa que Atlanta lesueuri tiene tendencia por las Aguas
Tropicales Superficiales (ATS) y aguas mezcladas con aguas de alta salinidad como las Aguas Subtropicales Superficiales (ASS).

$\mathrm{Su}$ mayor abundancia se la encontró en marzo del 2002 cuando en las regiones niño 3.4 y 1+2 habían anomalías positivas (Fig. 27). 

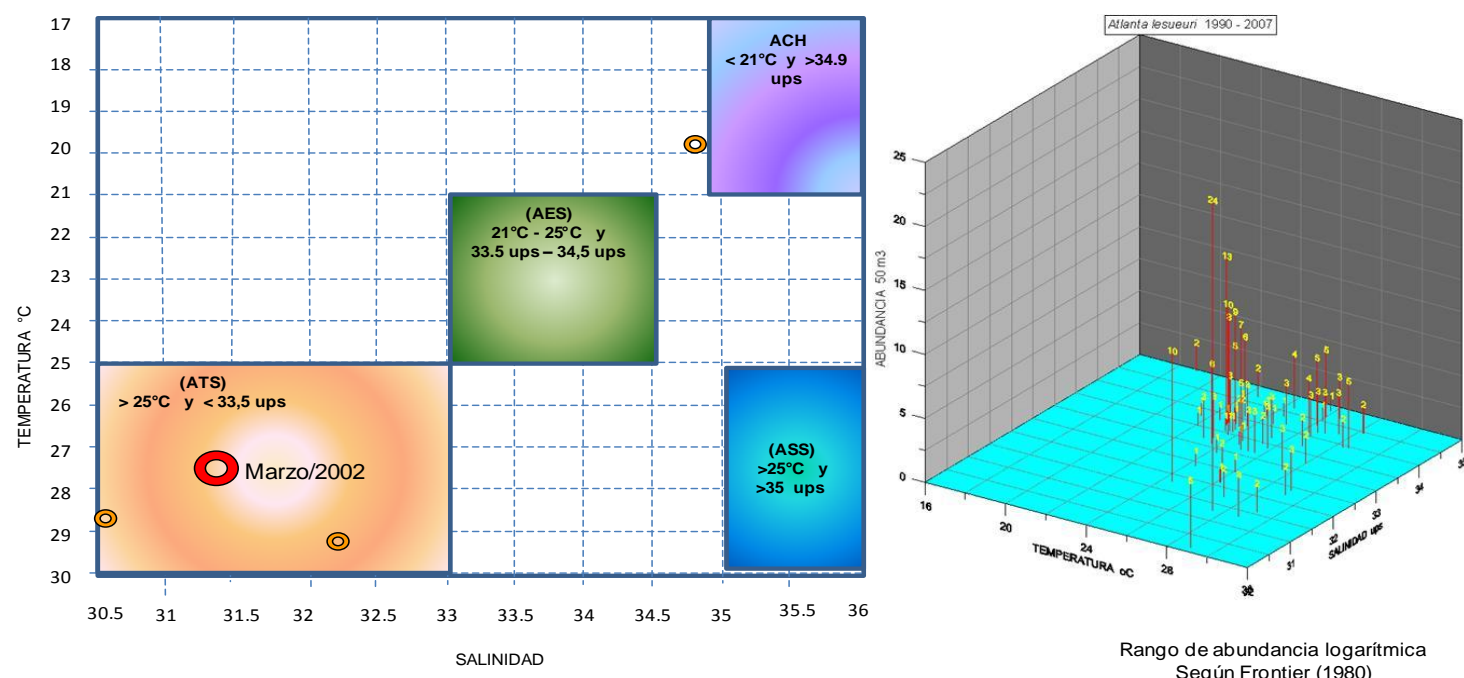

Fig.- 27.- Atlanta lesueuri. Se ha presentado con preferencia en Aguas Tropicales Superficiales (ATS) y en aguas frias con alta salinidad

Rango de abundancia log arítmica

\begin{tabular}{|lll|}
\hline \multicolumn{1}{|l|}{ Según Frontier (1980) } \\
\hline (O) & ESCASO & $1-3$ \\
(O) & FRECUENTE & $4-18$ \\
(O) & ABUNDANTE & $19-80$ \\
O & MUY ABUNDANTE & $81-350$ \\
\hline
\end{tabular}

Observaciones: En la estación de La Libertad, A. lesueuri se ha presentado con mucha frecuencia cuando hay anomalías positivas $\mathrm{y}$ eventos como El Niño, cuando hay un evento frío de La Niña, se ausenta o su presencia es mínima y esporádica. Es una especie que indica aguas cálidas y oceánicas.

\section{ATLANTIDAE \\ Atlanta peroni Lesueur 1817}

Conchilla con 4.5 a 5 vueltas, de las cuales la segunda vuelta es más angosta y fina que las demás, generalmente presentan una coloración café-rojiza, no presentan penetración de la carina en el enrollamiento de la concha. Del lado interno se observa un ombligo y se cuentan tres vueltas (foto 12)
En esta investigación se la ha considerado como Estenoterma y eurihalina en el mar ecuatoriano.

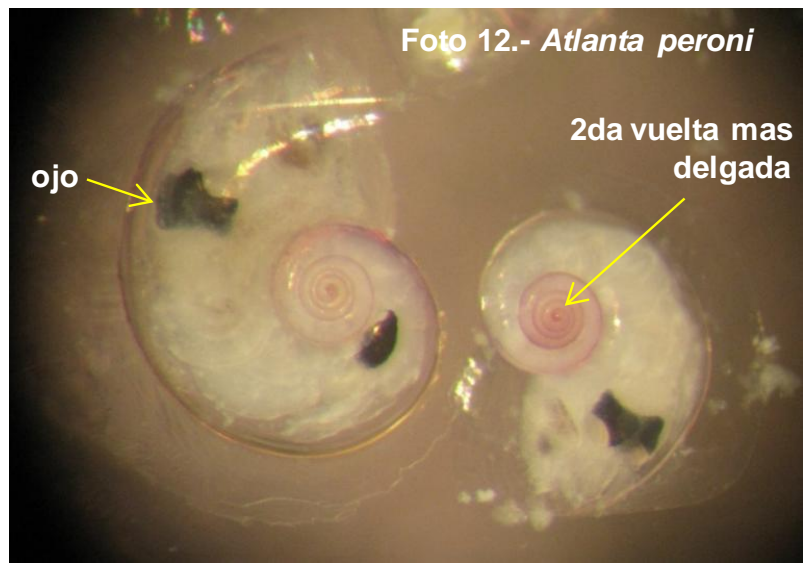

Atlanta peroni se ha presentado en temperaturas de $21.9^{\circ} \mathrm{C}$ a $29^{\circ} \mathrm{C}$ con preferencia entre $27.4^{\circ} \mathrm{C}$ a $28.5^{\circ} \mathrm{C}$ y en salinidades de 31.3 ups a 34.8 ups, con preferencia de 31.3 ups a 34.2 ups (Fig. 28).

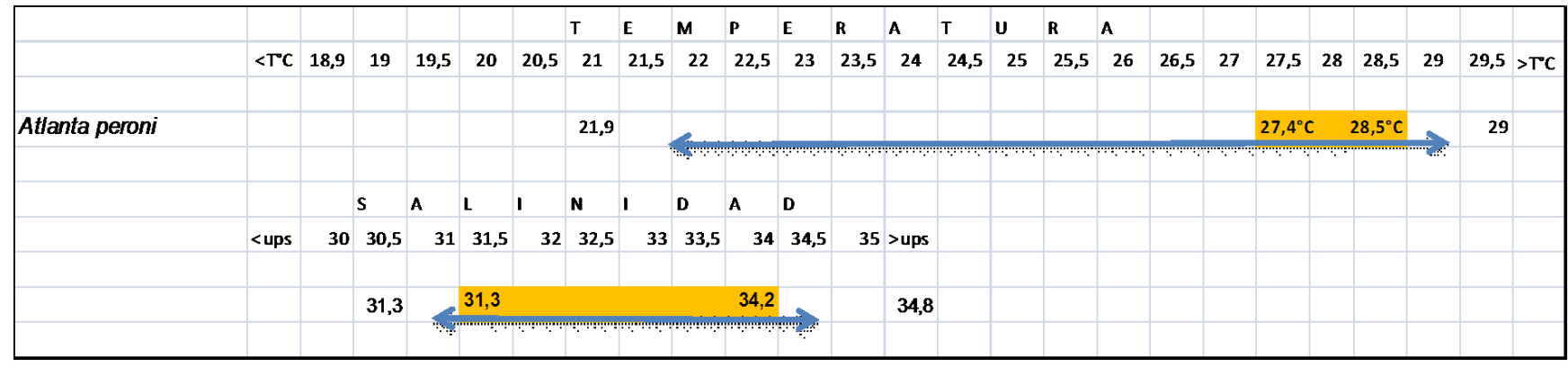


Se han encontrado 464 ejemplares en 64 observaciones realizadas con una abundancia máxima de 70 ejemplares, considerándose a esta especie como frecuente.

En el diagrama T-S se observa que Atlanta peroni tiene tendencia por las Aguas Tropicales Superficiales (ATS) y mezcladas con aguas de alta salinidad como las Aguas Subtropicales Superficiales (ASS).

Su mayor abundancia se la encontró en abril de 1992 cuando en las regiones niño 3.4 y $1+2$ estaba presente el evento El Niño (Fig. 29). Esta especie está relacionada con aguas cálidas y El Niño.

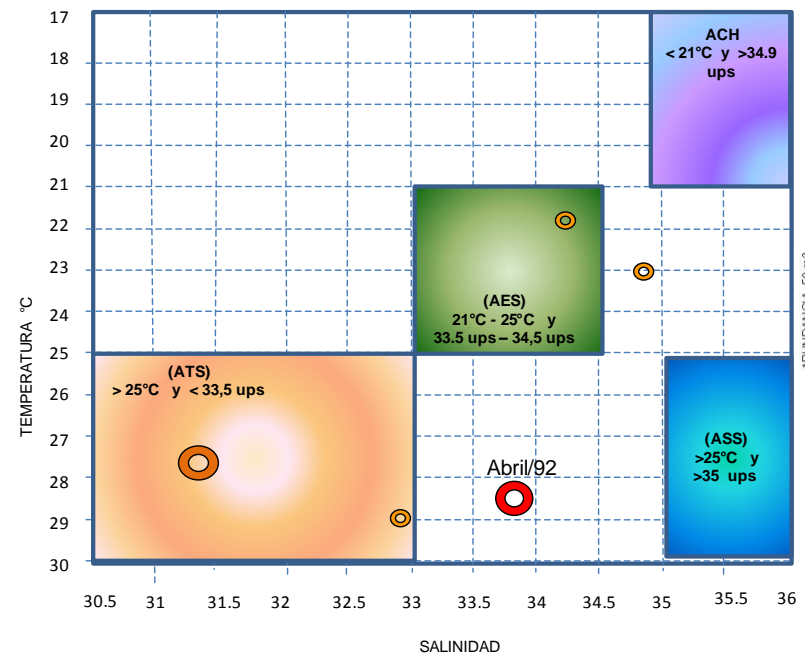

Fig. 29.- Atlanta peroni Se ha presentado en Aguas Tropicales Superficiales (ATS) $Y$ mezcladas con las Aguas Subtropicales Superficiales (ASS)

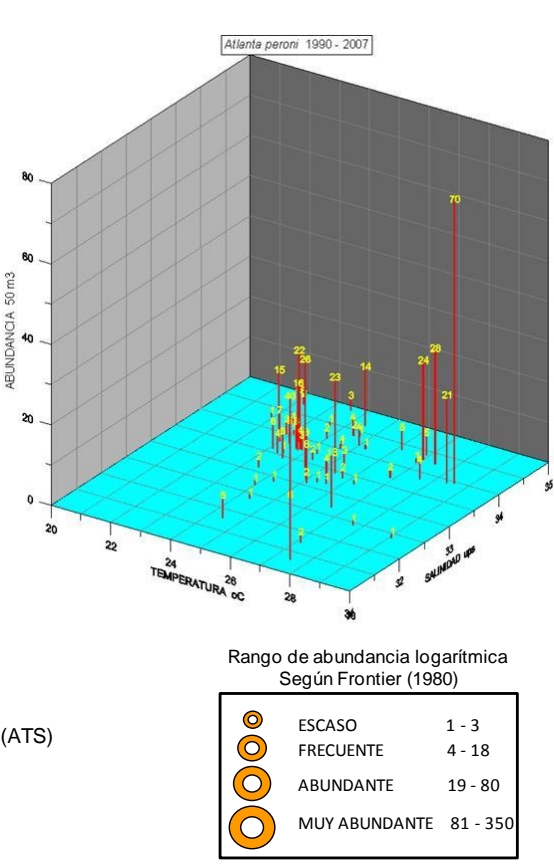

inclinada con 5 vueltas y media. El opérculo quitinoso, tiene bolitas o pústulas alrededor del núcleo (foto 13).

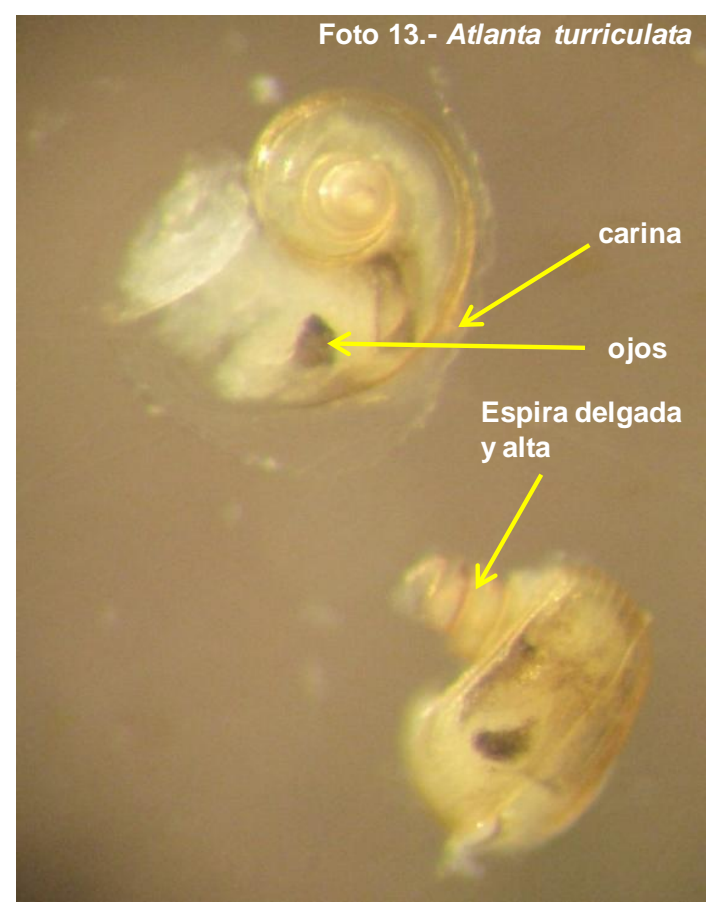


En este estudio se la ha considerado como una especie estenoterma y estenohalina en el océano Pacífico Ecuatoriano.

Esta especie se ha presentado en temperaturas de $21.7^{\circ} \mathrm{C}$ a $28.7^{\circ} \mathrm{C}$ con preferencia entre $24.9^{\circ} \mathrm{C}$ a $25.6^{\circ} \mathrm{C}$ y en salinidades de 31.3 ups a 34.6 ups, con preferencia de 33.1 ups a 33.8 ups (Fig. 30)

Se han encontrado 61 ejemplares en 28 observaciones realizadas con una abundancia máxima de 14 ejemplares, considerándose a esta especie como rara.
En el diagrama T-S se observa que Atlanta turriculata tiene tendencia por las Aguas Tropicales Superficiales (ATS) y aguas con salinidades de 33 ups, es decir, una mezcla de ATS y Aguas Subtropicales Superficiales (ASS).

$\mathrm{Su}$ mayor abundancia se la encontró en enero de 1993 cuando en la región 3.4 había anomalías positivas y en la región niño $1+2$ y estaba presente el evento El Niño (Fig. 31). Esta especie está relacionada con aguas cálidas.

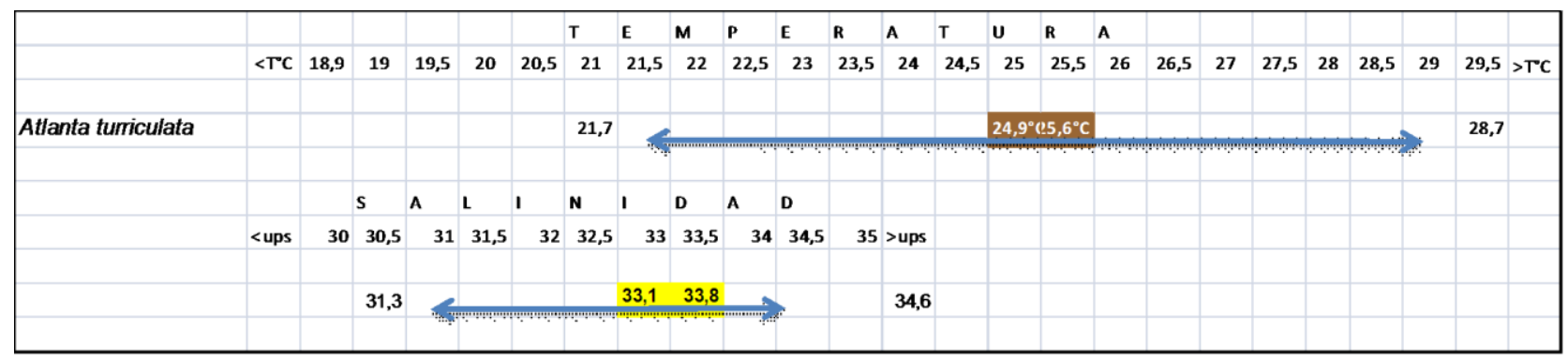

Fig. 30.- Rangos de tolerancia y preferencia de la temperatura y salinidad de Atlanta turriculata

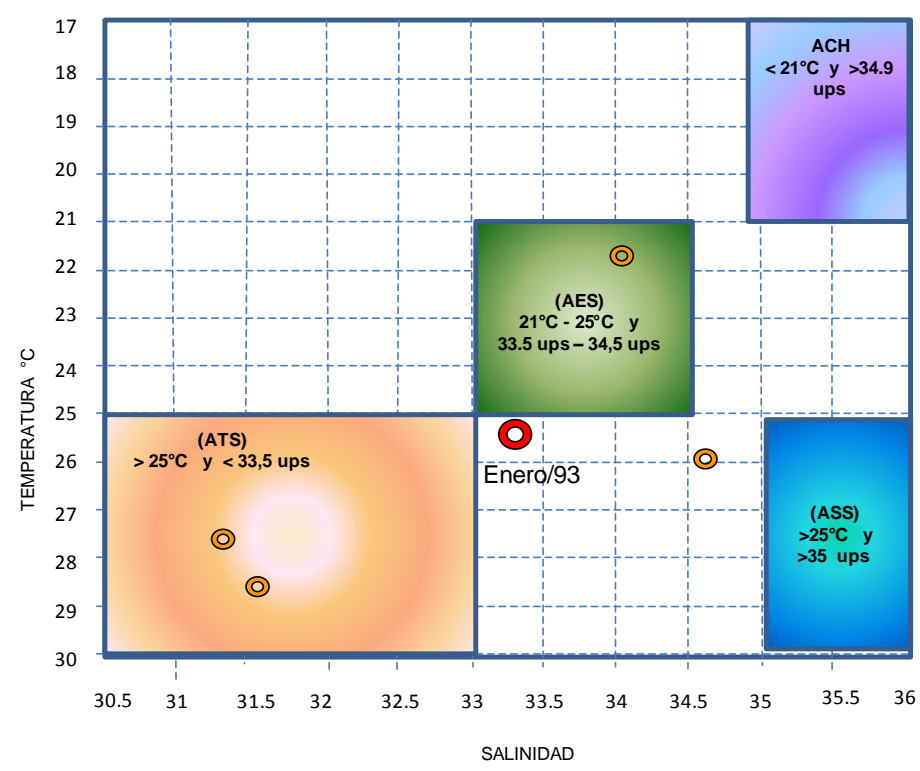

Fig. 31.- Atlanta turriculata. Se ha presentado en Aguas Tropicales Superficiales (ATS) y muestra una preferencia por la mezcla de (ATS) y Aguas Subtropicales Superficiales (ASS) por la preferencias a las aguas cálidas

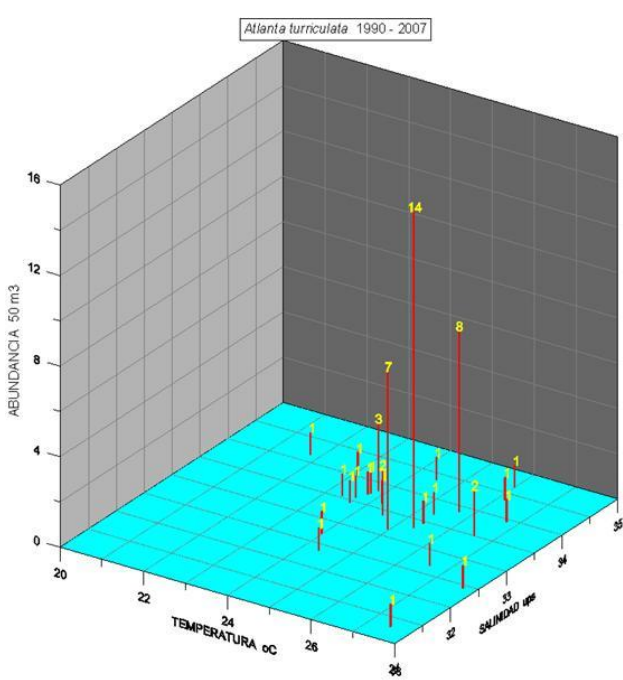

Rango de abundancia logarítmica Según Frontier (1980)

$\begin{array}{|lll|}\text { (a) } & \text { ESCASO } & 1-3 \\ \text { () } & \text { FRECUENTE } & 4-18 \\ \text { (O) } & \text { ABUNDANTE } & 19-80 \\ \text { (1) } & \text { MUY ABUNDANTE } & 81-350\end{array}$


Observaciones: Es una especie que está relacionada con aguas cálidas, su presencia fue mínima durante El Niño 1991-1992 y 19971998, mientras que durante los eventos fríos se ausenta. Es una especie bioindicadora de masas de aguas cálidas, pero su mínima abundancia con la que siempre se ha presentado, le resta un poco la importancia que tiene. Su presencia aumenta la certeza de la presencia de aguas oceánicas y cálidas frente a la costra ecuatoriana.

\section{Familia PTEROTRACHEIDAE}

\section{Firoloida desmarestia Lesuer 1817}

Organismo de forma cilíndrica, alargado, transparente, sin concha calcárea, el pie transformado en aleta con una ventosa en la parte anterior, posee tentáculos pre-orales (foto 14).
Es una especie euriterma y estenohalina en el mar Ecuatoriano.

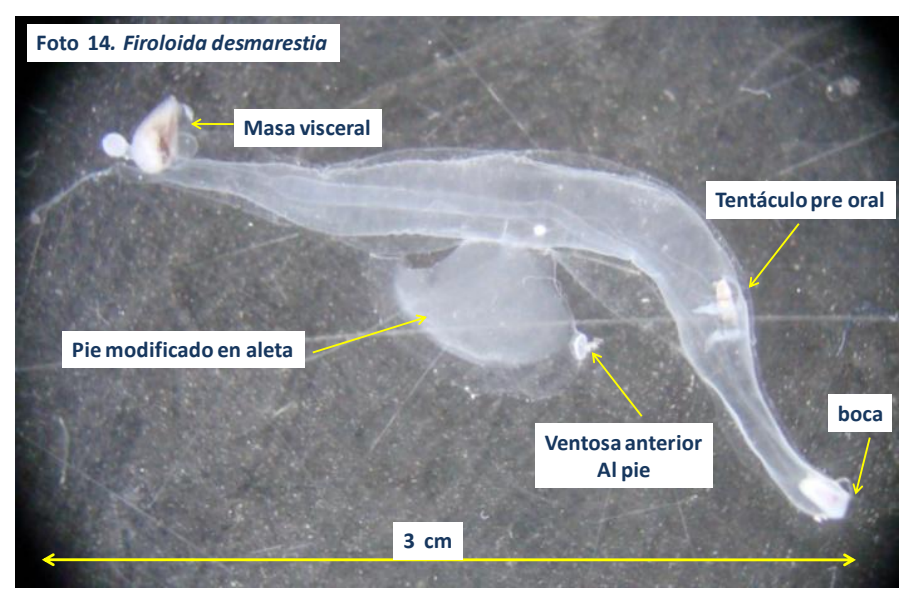

Firoloida desmarestia se ha presentado en temperaturas de $21.3^{\circ} \mathrm{C}$ a $29.1^{\circ} \mathrm{C}$ con preferencia entre $22.3^{\circ} \mathrm{C}$ a $26.3^{\circ} \mathrm{C}$ y en salinidades de 31.5 ups a 34.6 ups, con preferencia de 33.7 ups a 34.4 ups (Fig. 32).

\begin{tabular}{|c|c|c|c|c|c|c|c|c|c|c|c|c|c|c|c|c|c|c|c|c|c|c|c|c|c|}
\hline & & & & & & & $T$ & $\mathbf{E}$ & $\mathbf{M}$ & $\mathbf{P}$ & $\mathbf{E}$ & $\mathbf{R}$ & A & $\mathbf{T}$ & u & $\mathbf{R}$ & A & & & & & & & & \\
\hline & $<T^{\circ} \mathrm{C}$ & 18,9 & 19 & 19,5 & 20 & 20,5 & 21 & 21,5 & 22 & 22,5 & 23 & 23,5 & 24 & 24,5 & 25 & 25,5 & 26 & 26,5 & 27 & 27,5 & 28 & 28,5 & 29 & 29,5 & $>\mathrm{TC}$ \\
\hline \multirow[t]{4}{*}{ Firoloida desmaresti } & & & & & & 21,3 & & & & $22,3^{\circ} \mathrm{C}$ & & & & & & & & $26,3^{\circ} \mathrm{C}$ & & & & & & 29,1 & \\
\hline & & & s & $\mathbf{A}$ & $\mathbf{L}$ & $\mathbf{I}$ & $\mathbf{N}$ & I & D & $\mathbf{A}$ & D & & & & & & & & & & & & & & \\
\hline & <ups & 30 & 30,5 & 31 & 31,5 & 32 & 32,5 & 33 & 33,5 & 34 & 34,5 & 35 & >ups & & & & & & & & & & & & \\
\hline & & & & 31,5 & 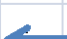 & & & & 33,7 & & 34,4 & & 34,6 & & & & & & & & & & & & \\
\hline
\end{tabular}

Fig. 32.- Rangos de tolerancia y preferencia de la temperatura y salinidad de Firoloida desmarestia

Se han encontrado 20 ejemplares en 10 observaciones realizadas con una abundancia máxima de 3 ejemplares, considerándose a esta especie como rara.

En el diagrama T-S se observa que Firoloida desmarestia tiene tendencia por las Aguas
Tropicales Superficiales (ATS) mezcladas con Aguas Subtropicales Superficiales (ASS).

Su mayor abundancia se la encontró en abril de 1993 cuando en la región 3.4 habían anomalías positivas y en la región niño $1+2$ y estaba presente el evento El Niño (Fig. 33). Esta especie está relacionada con aguas cálidas. 


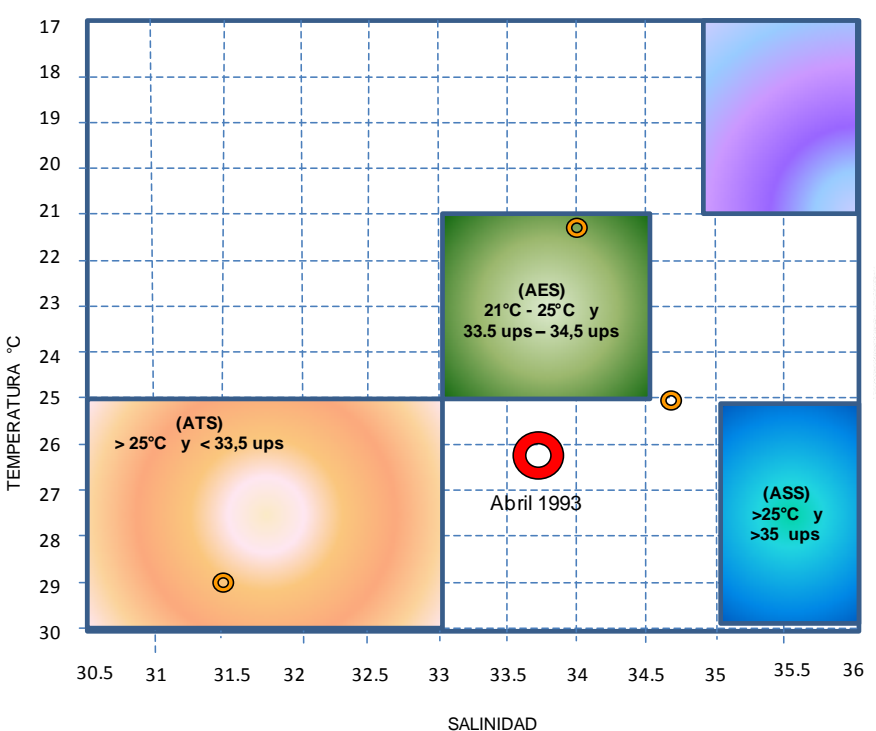

Fig. 33.- Firoloida desmarestia. Se ha presentado en Aguas Ecuatoriales Superficiales (AES), Aguas Tropicales Superficiales (ATS) y en aguas mezcladas de ATS y Aguas Subtropicales Superficiales (ASS)

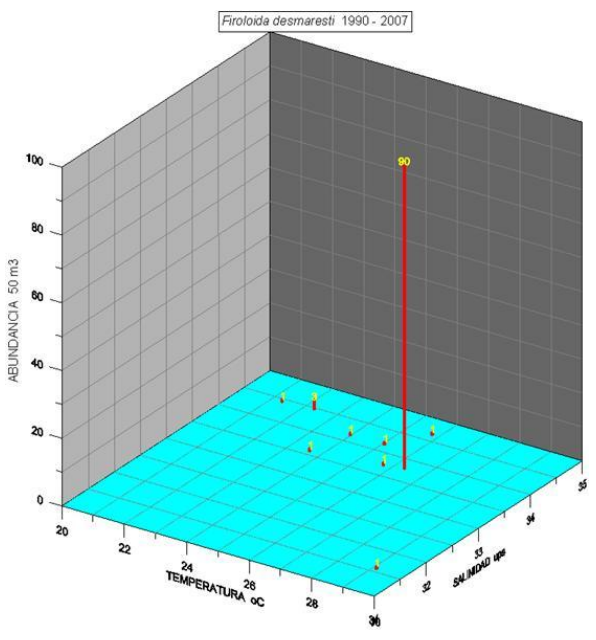

Rango de abundancia logarítmica Según Frontier (1980)

\begin{tabular}{|lll|}
\hline (2) & ESCASO & $1-3$ \\
() & FRECUENTE & $4-18$ \\
() & ABUNDANTE & $19-80$ \\
$(0)$ & MUY ABUNDANTE & $81-350$ \\
\hline
\end{tabular}

Observaciones: Es una especie escasa, con preferencia por las aguas de mayor salinidad, en una sola ocasión se presentó muy abundante cuando en la región $1+2$ se desarrollaba un evento cálido. También se la ha observado en eventos fríos en el primer semestre del 2000. Por su escasa abundancia, poca frecuencia de presencia y no define un ambiente, se considera que no es un bioindicador de masas de aguas.

\section{CONCLUSIONES}

Los rangos de tolerancia permitieron clasificar a las especies de la siguiente manera:

- Euritermos: Creseis vírgula, Creseis acicula, Cavolinia uncinata, Limacina trochiformis y Atlanta gaudichaudi, Atlanta lesueuri y Firoloida desmarestia.

- Estenotermos: Hyalocylis striata, Atlanta peroni, Atlanta turriculata, Desmopterus papilio, Cavolinia longirostris, Diacria quadridentata, y Limacina bulimoides,

- Eurihalinos: Creseis vírgula, Hyalocylis striata, Atlanta lesueuri, Atlanta peroni, Diacria quadridentata, Atlanta gaudichaudi.
- Estenohalinos: Creseis acicula, Atlanta turriculata, Firoloida desmarestia, Desmopterus papilio, Cavolinia longirostris, Limacina bulimoides, Cavolinia uncinata, y Limacina trochiformis

Considerando el comportamiento o reacción de cada especie con el tipo o masa de agua presente en la estación fija de La Libertad, su abundancia, correlación con las otras especies, calcificación de la concha, desarrollo del organismo entre otras observaciones, adicionalmente el autor de este trabajo ha podido clasificar a las especies de pterópodos y heterópodos como bioindicadores de masas de aguas de la siguiente manera:

- Muy buenos: Hyalocylis striata, Atlanta peroni y Atlanta lesueuri

- Buenos: Atlanta gaudichaudi, Atlanta turriculata, Desmopterus papilio y Limacina trochiformis

- Regular: Creseis vírgula, Cavolinia longirostris, y Diacria quadridentata.

- No responden: Limacina bulimoides, Cavolinia uncinata y Firoloida desmarestia. 
Es necesario mencionar, que esta clasificación es variable y puede cambiar, dependiendo de la asociación o conjunto que esté formando con las especies acompañantes, y el episodio que se esté desarrollando, como en el caso de At lanta gaudichaudi y Atlanta lesueuri, que pueden presentarse poco abundante, esporádica, e intermitente durante un evento frío de La Niña, sin que sean indicadores de masas de aguas frías, eso depende de su tolerancia eurihalina.

\section{BIBLIOGRAFÍA CITADA}

Bonilla, D. 1983. El zooplancton de las Islas Galápagos. Acta Oceanográfica del Pacífico., Vol. (2), No. 1, pp. 119-146

Cruz, M. 1983. Presencia de Pterópodos Tecosomados en el Golfo de Guayaquil. Acta Oceanográfica del Pacífico., Vol. (2), No. 1, pp. 179-186

-------. 1983.- Pterópodos y Heterópodos del Golfo de Guayaquil. Acta Oceanográfica del Pacífico. Vol. (2), No. 2, pp. 569-587

------. 1996.- Pterópodos tecosomados y Heterópodos (Gasterópodos) como Bioindicadores del Evento "El Niño" 1992, en la estación fija "La Libertad", Ecuador. Acta Oceanográfica del Pacífico. Vol. (8), No. 1, pp. 51-66

------. 2010.- Pterópodos y heterópodos como Bioindicadores del Evento "El Niño" y su relación con la temperatura y salinidad en la costa ecuatoriana (1990-2007. Tesis de Magister. Universidad de Guayaquil. pp. 1-107

-------. 1998.- Gasterópodos planctónicos (Pterópodos y Heterópodos) como Bioindicadores de los Eventos "El Niño" 1992 y 1997-1998, en la estación fija "La Libertad", Ecuador. Acta Oceanográfica del Pacífico. Vol. (9), No. 1, pp. 129-144
Enfield, David. 1975.- Oceanografía de la región norte del frente ecuatorial: Aspectos físicos. Publicación INOCAR. Dpto. de CDM. pp. 1-55

Frontier, S. 1963. Presence de Creseis chierchiae (Boas) Dans L' Ocean Indien. Cahiers O.R.S.T.O.M. Oceanographie, No. 6, (Serie Nosy-Be II).

-------. 1963. Heteropodes et Pteropodes recoltes dans le plankton de Nosy-Be, CAHIERS O.R.S.T.O.M. Oceanographie. No. VI

1973. Deuxieme liste complementaire des Pteropodes du plankton de Nosy-Be (Madagascar) et notes morphologiques. CAHIERS O.R.S.T.O.M. Oceanographie. Vol. (XI), No. 3, pp. 253-257

-------, 1980. Método de análisis rápido en muestras planctónicas. Acta Oceanográfica del Pacífico. Vol. (1), No. 1, pp. 137-145

Jiménez, R. 1975. Composición y variación de fitoplancton marino del Golfo de Guayaquil y áreas adyacentes. Tesis doctoral. Universidad de Guayaquil.

-------. 1976. Oceanografía de la Región Norte del Frente Ecuatorial: Aspectos Biológicos. Reunión de trabajo sobre el fenómeno conocido como El Niño, Guayaquil, Ecuador. 4-12 de diciembre de 1974. FAO Inf. Pesca (185): 335 348.

Jiménez, R. y D. Bonilla 1980. Composición y distribución de la biomasa del plancton en el frente ecuatorial. Acta Oceanográfica del Pacífico. Vol. (1), No. 1, pp. 19-64

Jiménez, R. 1983. Diatomeas y Silicoflagelados del fitoplancton del Golfo de Guayaquil. II 
edición. Acta Oceanográfica del Pacífico. Vol. (2), No. 2, pp. 193-281

2008. Aspectos biológicos de El Niño en el Océano Pacífico Ecuatorial. Edición de la Universidad de Guayaquil, Facultad de Ciencias Naturales-Centro de Biodiversidad CENBIO. Guayaquil, Ecuador. pp. 330.

Keen, M. 1971.- Sea shells of tropical West America; Marine mollusks from Baja California to Perú. Second edit. Stanf. Univ. Calif., pp. 1-1064.

Luzuriaga de Cruz, M. 1976. Foraminíferos Planctónicos vivos en aguas superficiales ecuatorianas durante El Niño de 1972. Publicación INOCAR. IOA-CM-BIO-09. pp. 1-30. Guayaquil-Ecuador.

1980. Sistemática y Ecología de los Foraminíferos Planctónicos vivos en el mar Ecuatoriano. Tesis Doctoral. Facultad de Ciencias Naturales de la Universidad de Guayaquil.

Magaldi, N. 1974. Moluscos holoplanctónicos del Atlántico Sudoccidental, I. Pterópodos Euthecosomados, colectados por el "Atlantis II" en Marzo de 1971. Com. Soc. Malac. Uruguay. 4 (27): 1-20

1977. Moluscos holoplanctónicos del Atlántico Sudoccidental. III. Heterópodos y Pterópodos de aguas superficiales Brasileñas y Uruguayas. Com. Soc. Malac. Urug. Vol. (IV), No. 33, pp. 295-323.

Matsubara, J.A. 1975. Sistemática, distribución, abundancia y relaciones ambientales de los Pterópodos tecosomados de la Bahía de Campeche, México. Tesis profesional de la Univ. Autónoma de México Fac. CC. Tabla 1, Figs. 10, pp. 1-51
Miró M, D. de y M. Luzuriaga 1974.Foraminíferos planctónicos vivos en aguas superficiales ecuatorianas. Publicación INOCAR. CM-BIO-3-74. pp. 1-14 GuayaquilEcuador

Okuda, T., M. Valencia y R. Trejos de Suescum., 1983 Nutrientes en las aguas superficiales y subsuperficiales en el área frente al Ecuador. Acta Oceanográfica del Pacífico. Vol. 2 No. 1, pp. 31-51

Pesantes, F. 1980. Distribución de los Dinoflagelados en el fitoplancton del mar ecuatoriano. Tesis doctoral. Universidad de Guayaquil.

------. 1983. Los dinoflagelados como indicadores de "El Niño" en el mar ecuatoriano. Acta Oceanográfica del Pacífico. Vol. (2) No. 1, pp. 86-117

Tesch, J.J. 1946.- The thecosomatous Pteropods. I. The Atlantic. Dana report. No. 28, pp. 82

1948. The Thecosomatous Pteropods. II. The Indo-Pacific. Report. No. 30, pp. 1-45, pl. 3

1949. Heteropoda. Dana Report. No. 34, pp. 1-53, pl. I-IV

Tokioka, T. 1951 Droplets from the plankton net. Seto. Mar. Biol. Lab., 1(4), pp. 183-184.

1955. Shells of Atlantidae (Heteropoda) collected by the Soyu-Maru in the Southern water of Japan. Publ. Seto. Mar. Biol. Lab., IV (2-3) pl. 17-18, Text, figs. 10

Van der Spoel, S. y D. Boltovskoy 1981. Atlas de zooplancton del Atlántico Sudoccidental. Pterópoda. Publ. Esp. INIDEP. Mar del Plata. Argentina. pp. 493-530 
2007. El Niño 2006-2007. Desarrollo y Manifestaciones en aguas ecuatorianas. Acta Oceanográfica del Pacífico. Vol. (14), No.1, pp. 1-6

\section{PÁGINAS WEB CONSULTADAS}

1. http://www.fao.org/docrep/009/a0086s/A00 86S06.htm

2. http://ecotoxicologiayecologia.blogspot.com /2012/05/tolerancia-la-temperatura-y-la.html 